Article

\title{
IR-UWB Pulse Generation Using FPGA Scheme for through Obstacle Human Detection
}

\author{
Lalida Tantiparimongkol and Pattarapong Phasukkit* \\ Department of Electronics Engineering, Faculty of Engineering, King Mongkut's Institute of Technology \\ Ladkrabang, Bangkok 10520, Thailand; 61601146@kmitl.ac.th \\ * Correspondence: pattarapong.ph@kmitl.ac.th
}

Received: 30 May 2020; Accepted: 2 July 2020; Published: 4 July 2020

\begin{abstract}
This research proposes a scheme of field programmable gate array (FPGA) to generate an impulse-radio ultra-wideband (IR-UWB) pulse. The FPGA scheme consists of three parts: digital clock manager, four-delay-paths stratagem, and edge combiner. The IR-UWB radar system is designed to detect human subjects from their respiration underneath the rubble in the aftermath of an earthquake and to locate the human subjects based on range estimation. The proposed IR-UWB radar system is experimented with human subjects lying underneath layers of stacked clay bricks in supine and prone position. The results reveal that the IR-UWB radar system achieves a pulse duration of $540 \mathrm{ps}$ with a bandwidth of $2.073 \mathrm{GHz}$ (fractional bandwidth of 1.797). In addition, the IR-UWB technology can detect human subjects underneath the rubble from respiration and identify the location of human subjects by range estimation. The novelty of this research lies in the use of the FPGA scheme to achieve an IR-UWB pulse with a $2.073 \mathrm{GHz}(117 \mathrm{MHz}-2.19 \mathrm{GHz})$ bandwidth, thereby rendering the technology suitable for a wide range of applications, in addition to through-obstacle detection.
\end{abstract}

Keywords: IR-UWB radar; FPGA; delay-line; human through-obstacle detection; range estimation; respiratory rate; doppler frequency

\section{Introduction}

Radar technology first emerged during World War II [1] and has evolved ever since. Apart from military operations, modern radar technology is deployed in numerous applications, including range/speed detection, autonomous driving vehicles [2-5], detection of objects buried underground (e.g., landmines or pipelines) [6-10], detection of airborne objects [11-13], and bio-radiolocation.

In bio-radiolocation, the Doppler radar principle is utilized to remotely detect human life using phase shift of the reflected signal from physiological movements, such as respiration, heartbeat, limb motion [14,15]. In [14], Doppler frequency was used to detect human life through an obstacle (i.e., through-wall detection). Additionally, the Doppler radar method is adopted for medical diagnostics, including sleep apnea, sudden infant death syndrome, and respiratory muscle weakness [16-21].

In through-wall detection, there are three conventional radar technologies: continuous wave (CW), frequency-modulated continuous-wave (FMCW), and step frequency continuous wave (SFCW) radars. In [22-24], CW radar technology was employed to detect human vital signs underneath the rubble. However, CW radar technology fails to estimate the range (location) of the human buried underneath and requires very strong vital signs for reliable detection [25]. As a result, FMCW and SFCW radar technologies were proposed to address the drawbacks [26-28]. Nevertheless, CW, FMCW, and SFCW radars suffer from limited penetration capability [29].

Ultra-wideband (UWB) radar is an unmodulated radar technology that transmits signals across a much wider frequency than conventional radar systems (CW, FMCW, and SFCW). The advantages of 
UWB radar include high-resolution range measurement, high penetrability, multi-target detection, low susceptibility to atmospheric conditions, detection of barely discernible vital signs, and low power transmission [30-32]. As a result, UWB radar technology is widely used for through-wall detection. In addition, UWB radar with S-band frequency (2-4 GHz) can penetrate non-metal solid objects and detect human respiration behind the obstacle [33]. Specifically, UWB radar technology holds promising potential for human detection buried underneath the rubble in the wake of an earthquake.

A field programmable gate array (FPGA) is an integrated circuit which is configurable by a system designer ex post. The advantages of FPGA are high-speed and parallel processing, reconfigurability, and design flexibility [34-37]. In [38,39], FPGA was deployed to process received signals of through-wall radar systems.

In [40-42], integrated circuits (IC) based on complementary metal oxide semiconductor (CMOS) technology were proposed for UWB pulse generation, but the CMOS-based IC suffer from restricted UWB bandwidth. In [43], FPGA was used to generate UWB pulse with a center frequency of $110.25 \mathrm{MHz}$ and a bandwidth of $41.5 \mathrm{MHz}$ (fractional bandwidth of 0.376), rendering it unsuitable for through-wall detection. Based on [43], FPGA was used to generate IR-UWB pulse to improve transmitting frequency bandwidth for radar application, and the proposed FPGA scheme could achieve a bandwidth of $1.6 \mathrm{GHz}$ (fractional bandwidth of 1.033) [44]. In [45], the FPGA scheme was further developed to detect live human subjects behind the wall by arm swing motion. The scheme achieved a bandwidth of $3.83 \mathrm{GHz}$ (fractional bandwidth of 2) and could estimate the range of human subjects by using statistical standard deviation (SD). Table 1 compares previous works on IR-UWB technology and this current research.

Table 1. Comparison between previous works on impulse-radio ultra-wideband (IR-UWB) technology and this current research.

\begin{tabular}{|c|c|c|c|}
\hline Specifics & Ref. [44] & Ref. [45] & Current Research \\
\hline IR-UWB bandwidth & $1.6 \mathrm{GHz}$ & $3.83 \mathrm{GHz}$ & $2.19 \mathrm{GHz}$ \\
\hline Fractional bandwidth & 1.033 & 2 & 1.797 \\
\hline Pulse repetition frequency (PRF) & $\begin{array}{l}200 \mathrm{MHz}, \\
400 \mathrm{MHz}\end{array}$ & $20 \mathrm{MHz}$ & $20 \mathrm{MHz}$ \\
\hline Signal amplitude & $611 \mathrm{mV}$ & $432 \mathrm{mV}$ & $456 \mathrm{mV}$ \\
\hline Human detection method & N/A & $\begin{array}{l}\text { Arm swing motion } \\
\text { (macro-doppler) }\end{array}$ & $\begin{array}{l}\text { Vital sign (respiration) } \\
\text { (micro-doppler) }\end{array}$ \\
\hline Range estimation method & $\mathrm{N} / \mathrm{A}$ & Standard Deviation & 7th moment \\
\hline Range validation & $\mathrm{N} / \mathrm{A}$ & Yes & Yes \\
\hline Macro/Micro doppler validation & $\mathrm{N} / \mathrm{A}$ & No & $\begin{array}{c}\text { Yes } \\
\text { (Respiration sensor) }\end{array}$ \\
\hline
\end{tabular}

This research thus proposes an FPGA scheme to generate IR-UWB pulse to detect from respiration live humans underneath the rubble and to estimate the range in order to locate the human subjects buried underneath. The FPGA scheme consists of three parts: digital clock manager, four-delay-paths stratagem, and edge combiner. Discrete fast Fourier transform is utilized to detect the respiration in terms of doppler frequency, and statistical 7th moment is used to locate human subjects in the range estimation. The proposed IR-UWB radar system is experimented with human subjects lying underneath different layers of stacked clay bricks in supine and prone positions.

The organization of this research is as follows: Section 1 is the introduction. Section 2 describes the proposed FPGA scheme and IR-UWB pulse generation. Section 3 details the human vital sign detection and range estimation algorithms. Section 4 deals with the experimental setup and method, and Section 5 discusses the experimental results. The concluding remarks are provided in Section 6.

\section{IR-UWB Pulse Generation and FPGA Scheme}

This section describes the ultra-wideband (UWB) pulse mathematical model and the proposed field programmable gate array (FPGA) scheme to generate an impulse radio ultra-wideband (IR-UWB) pulse. 


\subsection{UWB Pulse Mathematical Model}

The UWB pulse signal is mathematically characterized by Gaussian distribution function, which is expressed in Equation (1) [46]:

$$
G(t)=A_{0} e^{-\frac{1}{2}\left(\frac{t}{a}\right)^{2}}
$$

where $A_{0}$ is the transmission signal amplitude and $a=\tau / \sqrt{ } 2$ where $\tau$ is UWB pulse width.

The multi-order differential Gaussian distribution function is expressed in Equation (2), where $H_{n}(t)$ is Hermite polynomials that describe differential function (Equation (3)) and $n$ is differential order $(n=0,1,2,3, \ldots)$ ) [46,47]. Figure 1 illustrates the 0th, 1st, 2nd, and 3rd order UWB pulse signals using Equation (2):

$$
\begin{gathered}
G_{n}(t)=\frac{d^{n}}{d t^{n}} G(t)=(-1)^{n} \frac{1}{a^{n}} H_{n}(t) G(t) \\
H_{n}(t)=(-1)^{n} \frac{1}{a^{n}} e^{\frac{1}{2}\left(\frac{t}{a}\right)^{2}} \frac{d^{n}}{d t^{n}} e^{-\frac{1}{2}\left(\frac{t}{a}\right)^{2}}
\end{gathered}
$$
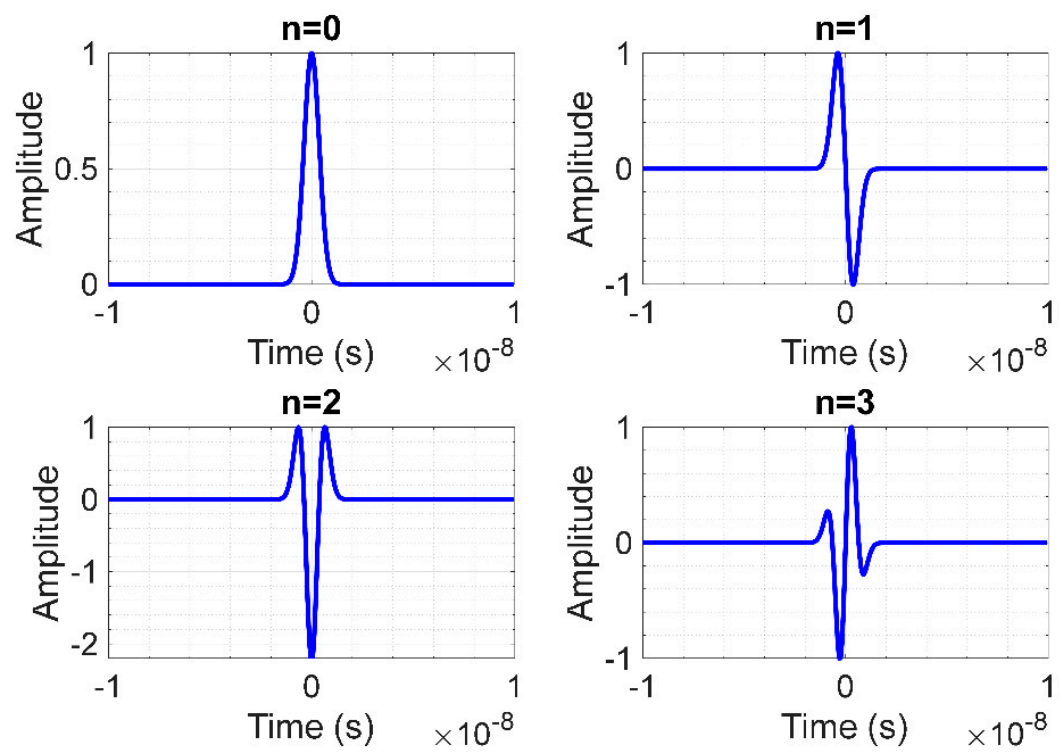

Figure 1. UWB pulse signals of 0th, 1st, 2nd, and 3rd order differential Gaussian distribution function.

Specifically, this research proposes a field programmable gate array (FPGA) scheme to generate impulse radio ultra-wideband (IR-UWB) pulse whose shape resembles the 0th order differential Gaussian distribution function $(n=0)$. The IR-UWB pulse signal, given $n=0$, is mathematically expressed in Equation (4) [48]:

$$
s(t)=A_{0} e^{-\left(\frac{t}{\tau}\right)^{2}}
$$

\subsection{Field Programmable Gate Array Scheme for IR-UWB Pulse Generation}

In [43], an FPGA scheme was experimented to generate a UWB pulse. The scheme could achieve a fractional bandwidth of 0.376 , with $110.25 \mathrm{MHz}$ center frequency, $41.5 \mathrm{MHz}$ bandwidth. Such a scheme also requires FPGA with tri-state buffers (TBUF). On the other hand, this current research proposes an FPGA scheme for generation of IR-UWB pulse in gigahertz $(\mathrm{GHz})$ frequency band for detection of live human subjects buried underneath the rubble in the aftermath of an earthquake. Unlike in [43], the proposed scheme utilizes generic FPGA to generate IR-UWB pulse (i.e., Virtex-6 FPGA ML605). 
The proposed IR-UWB FPGA scheme consists of three parts: digital clock manager, delay path stratagem, and edge combiner. Figure 2 illustrates the proposed FPGA scheme for IR-UWB pulse generation, where $t d$ is delay time of individual buffer logic gates in FPGA architecture.

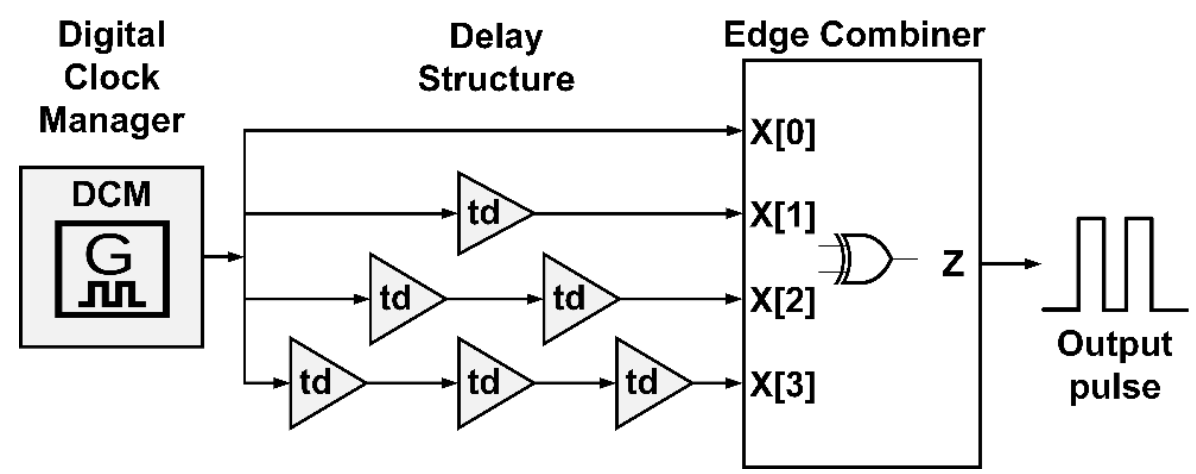

Figure 2. The proposed field programmable gate array (FPGA) scheme for IR-UWB pulse generation.

\subsubsection{Digital Clock Manager}

In the proposed scheme, the digital clock manager (DCM) in the FPGA intellectual property (IP) core is utilized to manipulate a low-voltage differential signaling (LVDS) oscillator. The LVDS oscillator is an on-board soldered clock source, resulting in highly reliable clock signal.

More specifically, the DCM manipulates the initial clock frequency of the LVDS oscillator to realize predetermined pulse repetition frequency (PRF). In this scheme, the PRF is twice the LVDS initial clock frequency. The initial clock frequency of the LVDS oscillator of Virtex-6 FPGA ML605 is $5 \mathrm{MHz}-200 \mathrm{MHz}$, giving rise to a wider range of PRF compared to [43]. Figure 3 shows the relationship between PRF and the initial clock frequency of LVDS oscillator.

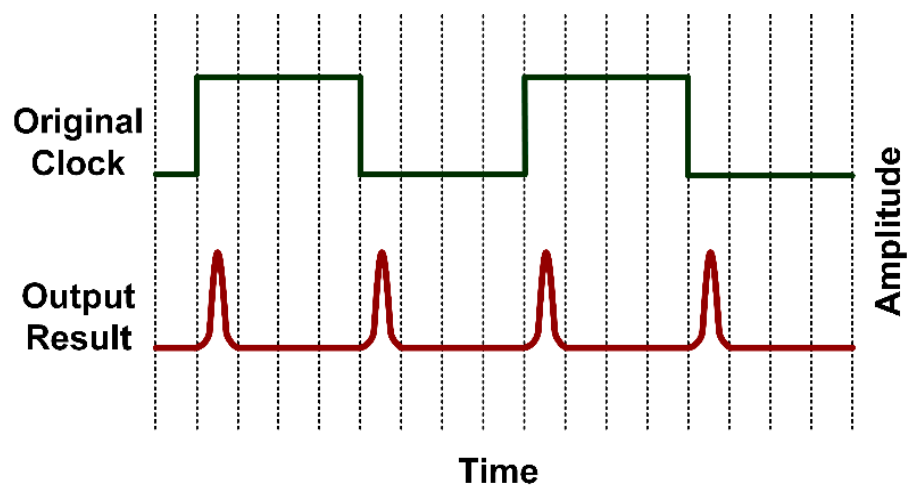

Figure 3. Relationship between pulse repetition frequency and initial clock frequency of low-voltage differential signaling (LVDS) oscillator.

\subsubsection{Delay Path Stratagem}

In FPGA, time-delay paths are predetermined by configuring the sequence of buffer logic gates. In this research, the delay path stratagem consists of four time-delay paths: $X[0], X[1], X[2]$, and $X[3]$, given $40 \mathrm{~nm}$ Virtex-6 FPGA ML605 [49]. The first delay path (X[0]) contains no delay time $(t d)$ and the second, third, and fourth delay paths (X[1], X[2], X[3]) have one, two, and three units of delay time, thereby resulting in staggered time-delay paths (Figure 4). To generate an IR-UWB pulse and achieve very broad bandwidth, a minimum delay time $(t d)$ is required. 


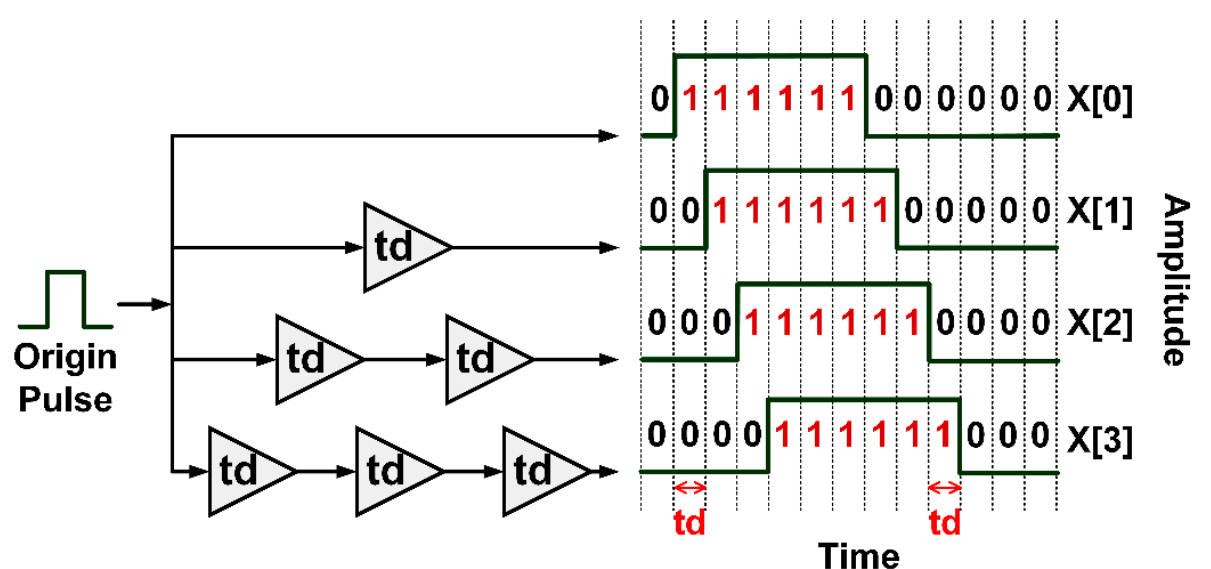

Figure 4. The staggered time-delay stratagem with four delay paths.

In order to realize the minimum delay time, the delay times of buffer logic gates in FPGA architecture are determined from the look up table (LUT) and the path with the minimum delay time is configurated by using a configuration logic block (CLB) based on the user constraint file. The place and route (P\&R) algorithm is implemented to route the configured buffer logic gates. The routing between buffer logic gates is validated by the Xilinx PlanAhead Design and Analysis Tool [50]. Figure 4 depicts the proposed staggered time-delay stratagem with four time-delay paths.

\subsubsection{Edge Combiner}

In the edge combiner part, exclusive OR (XOR) is applied to four staggered delay paths to achieve four narrow active pulses per cycle, where one active pulse is equal to one unit of delay time $(t d)$. LUT algorithm is utilized and functions as concurrent four-input XOR gate. The number of inputs is identical to the four time-delay paths in the delay path stratagem: $X[0], X[1], X[2]$, and $X[3]$. The output of the edge combiner (z) is fed into onboard coupling capacitor connected with $50 \Omega$ SMA connector to generate IR-UWB pulse (o) whose shape resembles the 0th order differential Gaussian distribution function $(n=0)$. The IR-UWB pulse width is approximately twice the delay time $(t d)$.

The advantages of the LUT algorithm are shorter processing time and lower time delay effect, vis-à-vis non-LUT edge combiner. Figure 5 illustrates the edge combiner with LUT algorithm as concurrent four-input XOR gate. Figure 6 shows the four staggered delay paths and four narrow active pulses per cycle, where $\mathrm{z}$ is the output of edge combiner.

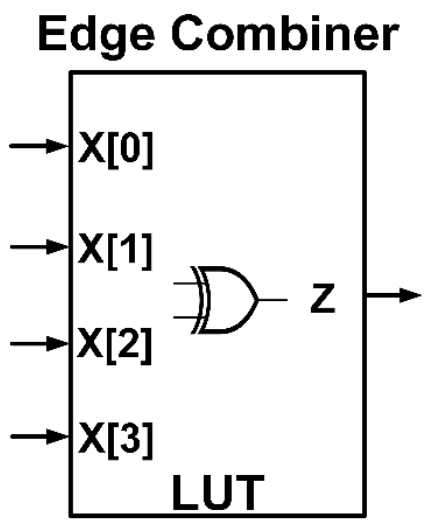

Figure 5. Edge combiner with look up table (LUT) algorithm as concurrent four-input XOR gate. 

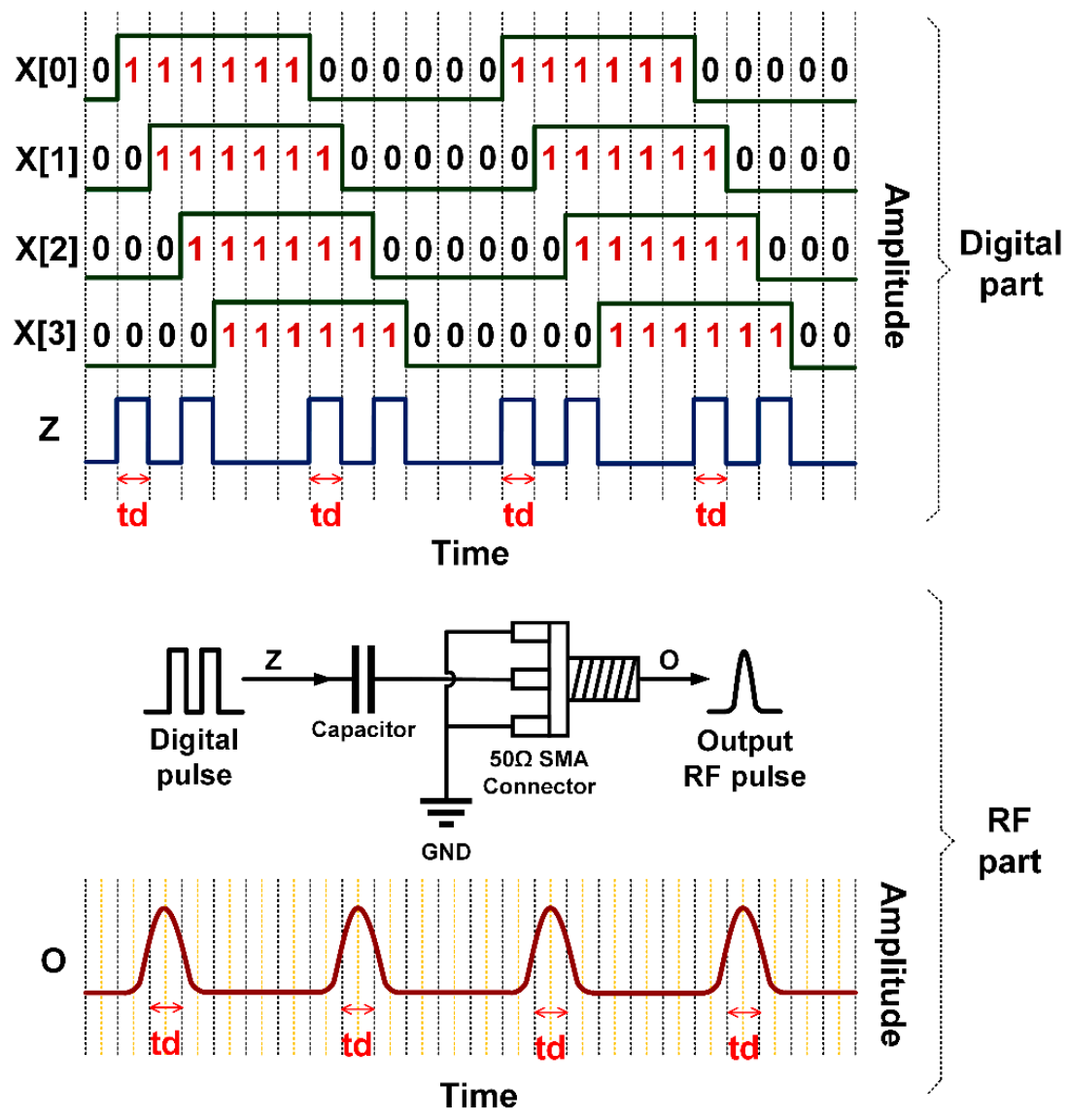

Figure 6. Application of XOR to four staggered delay paths (X[0], $X[1], X[2]$, and $X[3])$ for four narrow active pulses per cycle where $z$ is the output of edge combiner.

\section{Human Detection and Range Estimation Algorithms}

\subsection{Vital Sign Model Underneath the Rubble}

In theory, electromagnetic (EM) waves which are reflected off an object scatter and/or are captured by a receiver [51-56]. The back-scattered signal is mathematically written in Equation (5).

$$
R(t, \tau)=\sum_{p} \sigma_{p} s\left(t-t_{p}\right)+\sum_{o} \sigma_{o} s\left(t-t_{o}(\tau)\right)+\sum_{v} \sigma_{v} s\left(t-t_{v}(\tau)\right)
$$

where $\sigma_{p}, \sigma_{0}, \sigma_{v}$ are stationary, non-stationary, and human objects, $s\left(t-t_{v}\right)$ is time-shifting of the transmitted signal, $t$ and $\tau$ are fast-time and slow-time domains.

Figure 7 illustrates the reflected signals from the human subject and impenetrable solid object in fast time and slow time. The reflected signals from the human subject are periodic due to the vital signs, i.e., respiration and heartbeat. Meanwhile, the reflected signals from the solid object are static as they are not subject to time shift. As a result, human physiological movements can be determined by time shift of reflected signals.

Since this research focuses on human vital signs (i.e., reflected signals from human), the back-scattered signal in Equation (5) can be simplified as:

$$
R(t, \tau)=\sigma_{v} s\left(t-t_{v}(\tau)\right)
$$

where the time delay $\left(t_{v}(\tau)\right)$ is equal to $2 d(\tau) / c$, where $c$ is the speed of light $\left(3 \times 10^{8} \mathrm{~m} / \mathrm{s}\right)$. The distance between the transmitting $(T x)$ antenna and human subject $(d(\tau))$ is estimated by: 


$$
d(\tau)=d_{0}+d_{h} \sin \left(2 \pi f_{h} \tau\right)+d_{r} \sin \left(2 \pi f_{r} \tau\right)
$$

where $d_{0}$ is the nominal distance between the Tx antenna and human subject, $d_{h}$ and $d_{r}$ are the movement amplitudes of the heart and respiration, $f_{h}$ and $f_{r}$ are the frequencies corresponding to heartbeat and respiration. From Equation (7), the time delay function can be written in Equation (8):

$$
t_{v}(\tau)=2 d(\tau) / c=t_{0}+t_{h} \sin \left(2 \pi f_{h} \tau\right)+t_{r} \sin \left(2 \pi f_{r} \tau\right)
$$

where $t_{0}, t_{r}$, and $t_{h}$ are the delays related to the human distance, respiratory and heart motions, respectively.

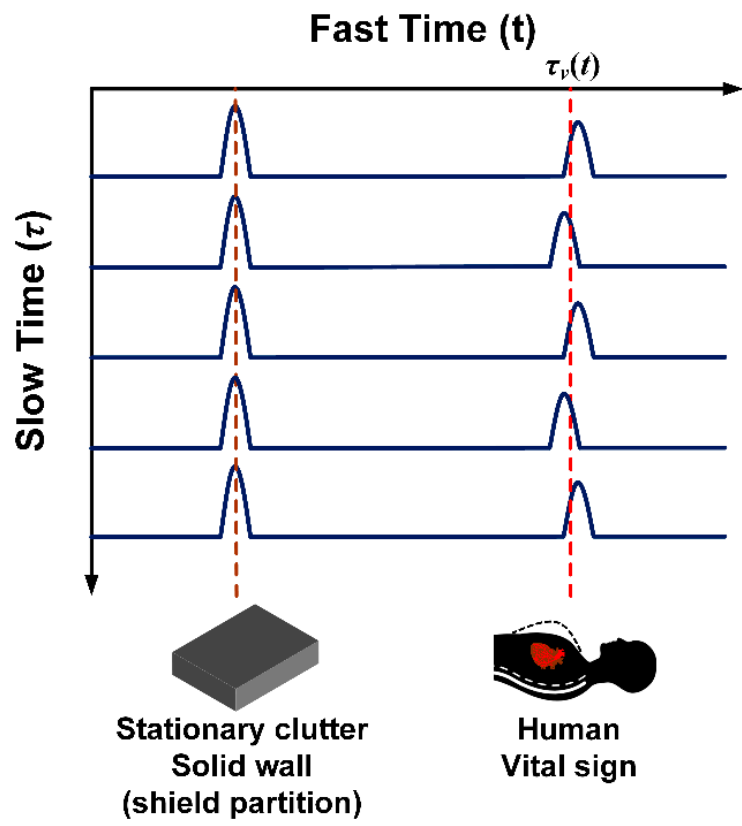

Figure 7. Reflected signals from human and solid object in fast time and slow time.

Figure 8 illustrates the distance between antenna and human subject $\left(d_{0}\right)$ as a function of the movement amplitudes of the heart $\left(d_{h}\right)$ and respiration $\left(d_{r}\right)$. The proposed through-obstacle IR-UWB radar is of classical monostatic radar, consisting of one Vivaldi transmitting (1-Tx) and one Vivaldi receiving (1-Rx) antenna.

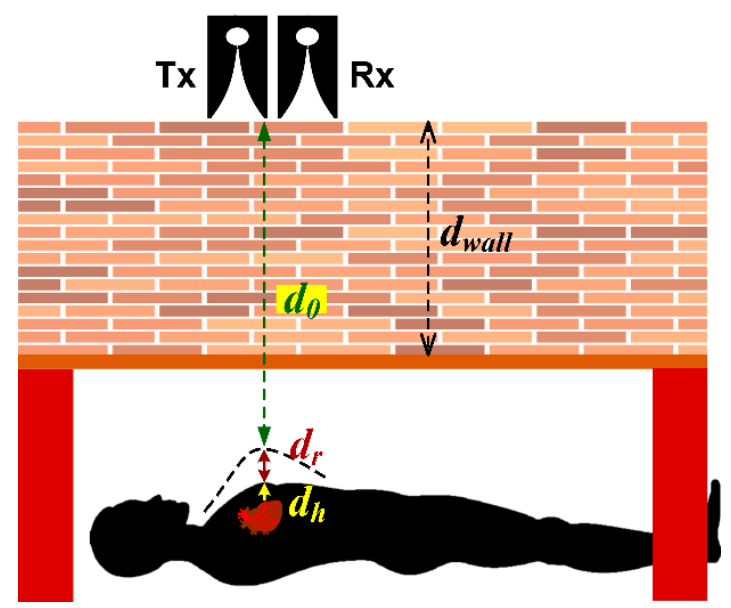

Figure 8. The distance between antenna and human subject as a function of the movement amplitudes of the heart and respiration. 
Due to challenges in measuring the back-scattered signal in continuous time (Equation (5)), this research characterizes the back-scattered signal in discrete time [51-57]. The back-scattered signal in discrete time $(R[k, l])$ is expressed in Equation $(9)$ :

$$
R[k, l]=h[k, l]+c[k, l]+w[k, l]+q[k, l]
$$

where $h[k, l], c[k, l], w[k, l]$, and $q[k, l]$ are the respiration and heartbeat signals, static signal, white noise, and non-static signal, respectively, where $k$ is discrete domain in fast time of $K$ sampling and $l$ is discrete domain in slow time of $L$ sampling. Preprocessing is subsequently performed to filter out unwanted signals (i.e., static signal, white noise, and non-static signal) to extract the vital signs.

\subsection{Preprocessing To Remove Unwanted Signals}

The back-scattered signal in discrete time is preprocessed to remove unwanted signals. The unwanted static signal $(c[k, l])$ is independent of slow time (Figure 7) and can be removed by averaging $l$ by the number of slow time sampling $(L)$. The discrete-time back-scattered signal with the unwanted static signal $(c[k, l])$ removed is expressed in Equation $(10)$ :

$$
\Omega_{n}[k, l]=R[k, l]-\frac{1}{L} \sum_{l=1}^{L} R[k, l]=h[k, l]+w[k, l]+q[k, l]
$$

In practice, the first and second pulses of back-scattered signal are the antenna coupling and wall/obstacle reflection, respectively. Given the antenna coupling and wall reflection at the minimum detectable range, this research designates the first and second pulses as zero:

$$
\Omega\left[1: K_{\text {zero }}, l\right]=0 \text {, where } K_{\text {zero }}=\text { floor } d_{\min } / \Delta d
$$

where $d_{\min }$ is the minimum detectable range and $\Delta d$ is the range resolution of radar depending on the speed of light $(c)$ and bandwidth $(B)$ where $\Delta d=\mathrm{c} / 2 \mathrm{~B}$.

The non-static signal $(q[k, l])$ and white noise $(w[k, l])$ are reduced by smooth filter (Equation $(12))$ and Butterworth bandpass filter (Equation (13)) in fast and slow-time domains:

$$
y[k, l]=\frac{1}{2 \lambda+1} \sum_{i=-\lambda}^{\lambda} \Omega[k-i, l]
$$

where $\lambda$ is the number of average data points on either side of $\Omega[k, l]$ and $2 \lambda+1$ is the span. The transfer function of Butterworth bandpass filter is expressed as:

$$
|H(\omega)|^{2}=\frac{1}{1+\left(\omega / \omega_{c}\right)^{2 N_{f}}}
$$

where $\omega_{c}$ is the cutoff frequency and $N_{f}$ is the filter order and set to 5 , giving a good tradeoff between performance and complexity [54]. The discrete-time back-scattered signal with unwanted signals removed is rewritten as:

$$
y[k, l] \approx h[k, l]+w_{0}[k, l]+q_{0}[k, l]
$$

\subsection{Respiratory Rate and Range Estimation}

The discrete fast Fourier transform (DFT) algorithm is applied to the discrete-time back-scattered signal in Equation (14) to determine doppler frequency (i.e., respiratory rate). The DFT of the refined discrete-time back-scattered signal is expressed in Equation (15). 


$$
Y[k, f]=\sum_{l=1}^{L} y[k, l] e^{-\frac{j 2 \pi f l}{L}}
$$

In range estimation, the statistical 7th moment is used to locate human subjects underneath the rubble. From Equation (14), the statistical 7th moment can be expressed in Equation (16), where Equation (17) is the mean of $y[k, l]$ in slow time. Figure $9 a, b$ respectively illustrates the DFT doppler frequency (respiration rate) and range estimation using the statistical 7th moment.

$$
\begin{gathered}
\mu_{7}=\frac{1}{L} \sum_{l=1}^{L}(y[k, l]-\bar{y}[k])^{7} \\
\bar{y}[k]=\frac{1}{L} \sum_{l=1}^{L} y[k, l]
\end{gathered}
$$
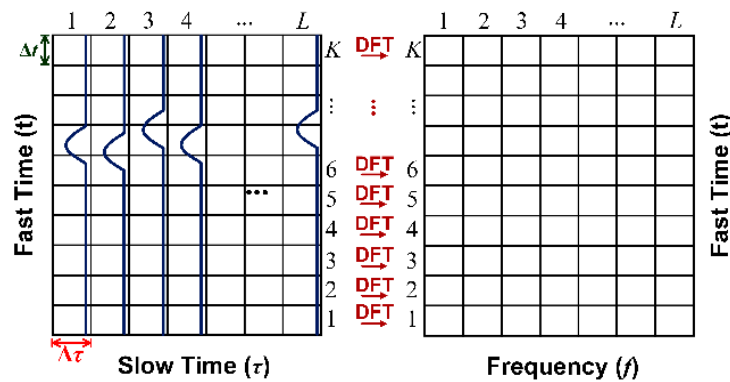

(a)

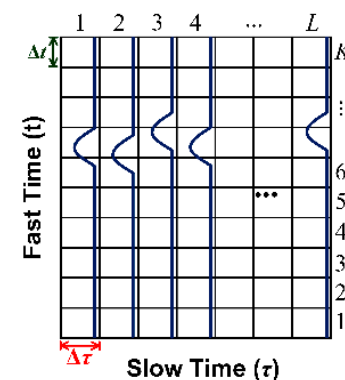

(b)

Figure 9. Respiration rate and range estimation: (a) DFT doppler frequency; (b) statistical 7th moment.

\section{Experimental Setup and Method}

This section deals with the generation of IR-UWB pulse using the proposed FPGA scheme and with detection of human subjects underneath the rubble using the FPGA scheme.

\subsection{IR-UWB Pulse Generation}

Figure 10 illustrates the schematic of IR-UWB pulse generation using the proposed FPGA scheme. The Verilog HDL programming language is used to create a user constraint file for selectively placing and routing buffer logic gates; and to regulate LVDS clock at $10 \mathrm{MHz}$. An FPGA bitstream file (.bit) is compiled and programmed into FPGA via Joint Test Action Group (JTAG) connector. The setup is verified by embedded hardware monitoring function ChipScope Pro Analyzer.

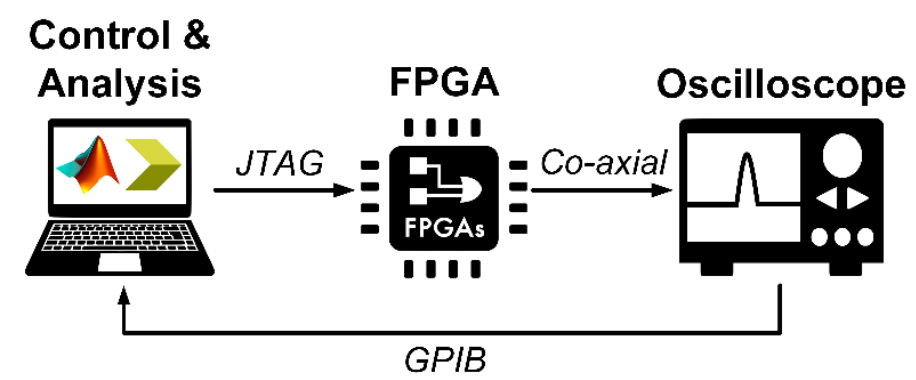

Figure 10. Schematic of IR-UWB pulse generation using the proposed FPGA scheme. 
The IR-UWB pulse from FPGA is fed into oscilloscope via co-axial transmission line. A computer is used to retrieve digital data via general purpose interface bus (GPIB) for MATLAB analysis to determine the pulse duration and bandwidth. Table 2 tabulates the experimental components and specifications.

Table 2. The specifications of experimental components.

\begin{tabular}{|c|c|c|}
\hline Components & Model Name & Specification \\
\hline $\begin{array}{l}\text { Oscilloscope } \\
\text { (ADC) }\end{array}$ & Tektronix, TDS7404B & $\begin{array}{l}\text { Digital Phosphor Oscilloscope } \\
\qquad(4 \mathrm{GHz}, 20 \mathrm{GS} / \mathrm{s})\end{array}$ \\
\hline FPGA & $\begin{array}{c}\text { Xilinx, } \\
\text { Virtex 6-ML605 } \\
\text { (XC6VLX240T) }\end{array}$ & $\begin{array}{l}\text { Total logic cell: } 241,152 \text { cells } \\
\text { Technology process: } 40 \mathrm{~nm} \\
\text { Copper CMOS process }\end{array}$ \\
\hline GPIB & $\begin{array}{c}\text { Agilent } \\
\text { Technologies, } \\
\text { 82357B }\end{array}$ & $\begin{array}{l}\text { USB/GPIB interface USB2.0, transfer rate } \\
\text { over } 850 \mathrm{~KB} / \mathrm{s}\end{array}$ \\
\hline $\begin{array}{l}\text { Power Amplifier } \\
\text { (PA) }\end{array}$ & $\begin{array}{l}\text { Mini Circuits, } \\
\text { ZVE-8G }\end{array}$ & $2 \mathrm{GHz}-8 \mathrm{GHz}$, Gain $=30 \mathrm{dBm}$ \\
\hline $\begin{array}{l}\text { Low Noise Amplifier } \\
\text { (LNA) }\end{array}$ & R\&K-AA260-0S & $2 \mathrm{GHz}-5 \mathrm{GHz}$, Gain $=26 \mathrm{dBm}$ \\
\hline Spectrum Analyzer & $\begin{array}{l}\text { Anritsu, } \\
\text { MS8609A }\end{array}$ & $\begin{array}{l}\text { Digital Mobile Radio Transmitter Tester, } \\
\qquad 9 \mathrm{kHz}-13.2 \mathrm{GHz}\end{array}$ \\
\hline Tx, Rx Antennas & Vivaldi antenna & $0.7 \mathrm{GHz}-2.5 \mathrm{GHz}$, Gain = $11 \mathrm{dBi}$ \\
\hline $\begin{array}{l}\text { Respiratory } \\
\text { measurement } \\
\text { sensor }\end{array}$ & $\begin{array}{l}\text { Great Lakes } \\
\text { Neurotechnologies, } \\
\text { BioRadio }^{\mathrm{TM}}\end{array}$ & $\begin{array}{l}\text { Wireless Biomedical monitor, } \\
\text { Chest Interface cables belt sensor. }\end{array}$ \\
\hline
\end{tabular}

\subsection{Detection of Human Underneath the Rubble}

To simulate detection of human subjects buried underneath the rubble, this research used layers of stacked clay bricks as a substitute for collapsed walls. Figure 11 depicts the experimental setup for detection of human subjects underneath layers of stacked clay bricks in supine and prone positions using the FPGA scheme. The human participants were instructed to remain physically stationary over the course of experiment.

In the experimental detection, there were three male and three female healthy participants. The human subjects individually lay underneath layers of stacked clay bricks with Tx and Rx Vivaldi antennas sitting atop. The distance between Tx and $R x$ antennas is $15 \mathrm{~cm}$, and the radar-antennas set is motionable horizontally and vertically.

The layers of stacked clay bricks on $1.5 \mathrm{~cm}$-thick plywood were varied between 3, 6, and 9 layers $(9,18$, and $27 \mathrm{~cm}$ in thickness). The distances between the Tx-Rx antennas and participating human subjects underneath the stacked clay bricks were $20.5-47 \mathrm{~cm}$, depending on the number of brick layers $(3,6$, and 9 layers) and gender. The vital sign detection experiments were carried out with participants in supine and prone position. The data acquisition duration for each individual participant in either position was 3 min with 256 slow-time pulses and 5000 fast-time datapoints.

In addition, the six participants wore a respiration sensor (BioRadio ${ }^{\mathrm{TM}}$ respiratory kit) around their chest to monitor respiration rhythm. The experimental measurement using the proposed IR-UWB FPGA scheme was validated against the readings by the respiration sensor. Figure 12 shows the schematic of IR-UWB pulse generation using FPGA scheme for detection of human subjects underneath layers of stacked clay bricks. The specifications of the experimental components and equipment are presented in Table 2. 


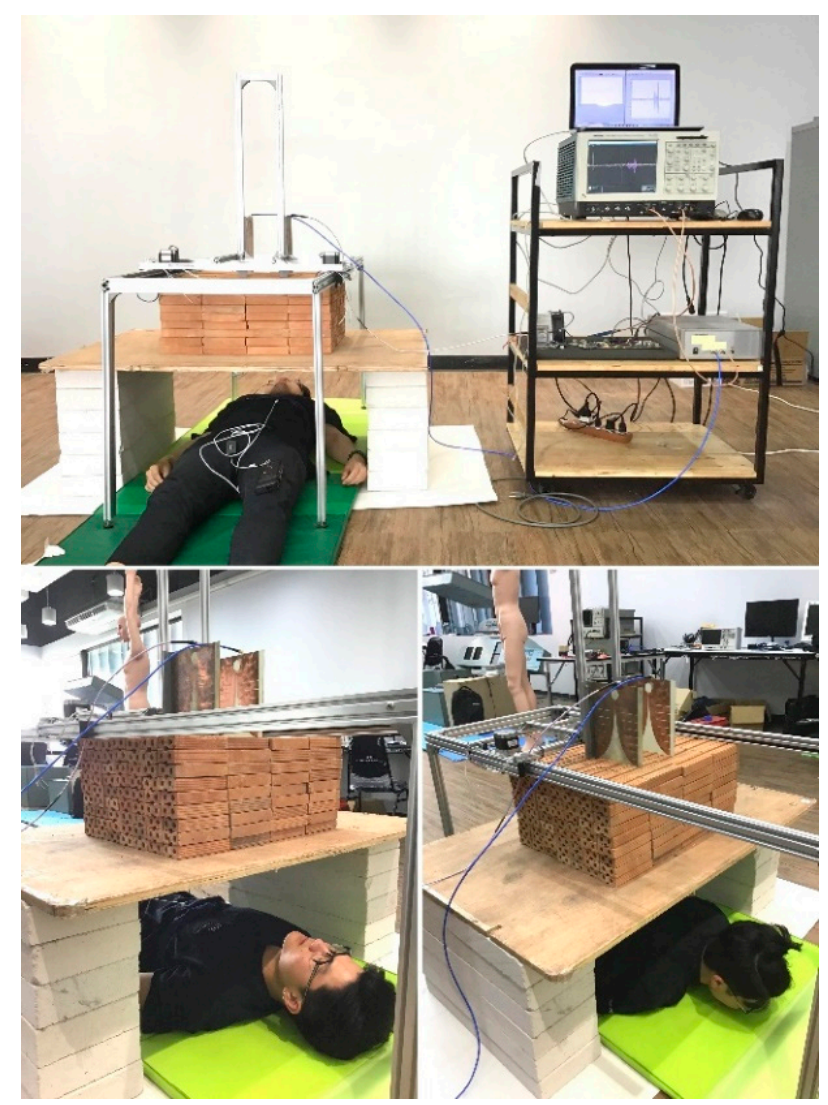

Figure 11. Experimental setup for detection of human subject underneath layers of stacked clay bricks in supine and prone positions using the FPGA scheme.

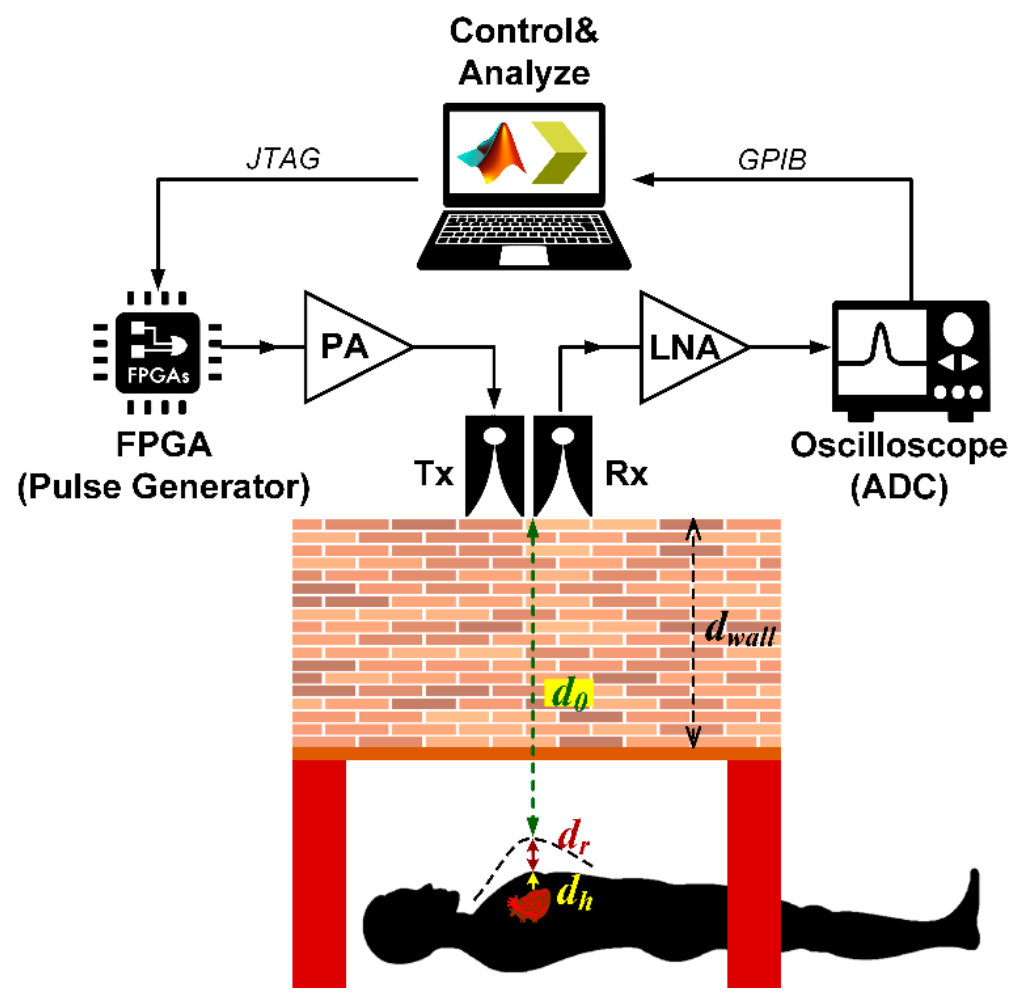

Figure 12. Schematic of IR-UWB pulse generation using FPGA scheme for detection of human subject underneath layers of stacked clay bricks. 


\section{Experimental Results and Discussion}

This section discusses IR-UWB pulse generated by the proposed FPGA scheme and the human detection performance of the IR-UWB radar system in terms of respiratory rate and range estimation.

\subsection{IR-UWB Pulse Generation Using FPGA Scheme}

Figure 13 illustrates the waveform of LUT four-input XOR gate by using ChipScope Pro Analyzer function. The waveform is identical to the schematic of four staggered delay paths and four narrow active pulses or delay time ( $t d$ ) per cycle (Figure 6). One unit of delay time $(t d)$ is approximately $270 \mathrm{ps.}$

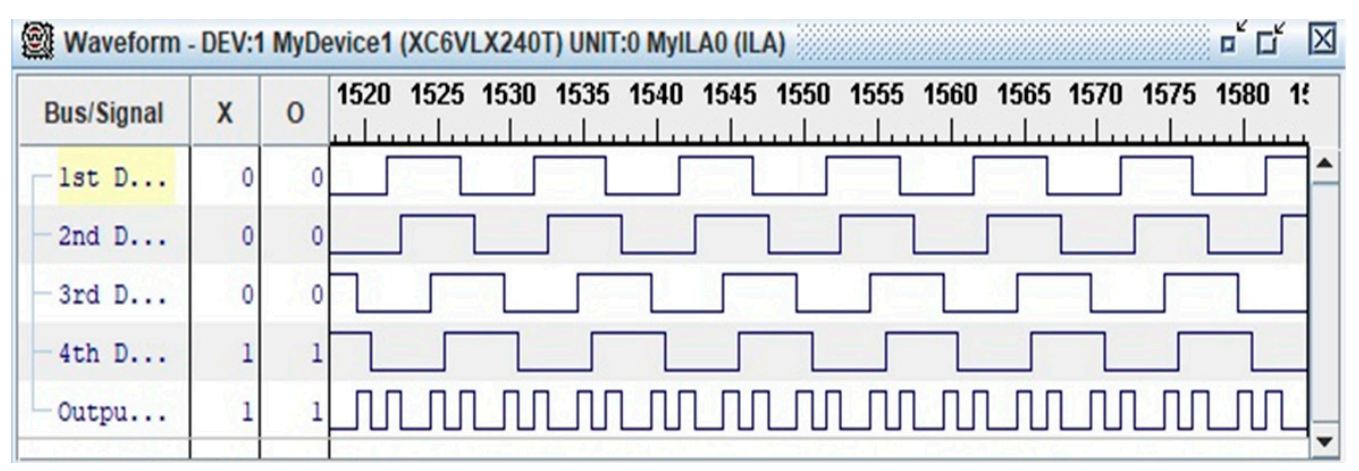

Figure 13. Waveform from ChipScope Pro Analyzer function.

Figure 14 depicts the IR-UWB pulse generated by the FPGA scheme with pulse repetition frequency (PRF) of $20 \mathrm{MHz}$ using oscilloscope. Given the LVDS clock of $10 \mathrm{MHz}$, the PRF of IR-UWB is $20 \mathrm{MHz}$, which is twice the LVDS clock frequency. The digital data from the oscilloscope and spectrum analyzer were retrieved via GPIB to characterize the pulse duration and bandwidth using MATLAB, as shown in Figure 15. The pulse duration is 540 ps, which is approximately twice the delay time $(t d)$, and the bandwidth is $2.073 \mathrm{GHz}(117 \mathrm{MHz}-2.19 \mathrm{GHz}$, fractional bandwidth of 1.797), given the Federal Communications Commission (FCC)'s normalized magnitude $\geq-10 \mathrm{~dB}$. The realized IR-UWB bandwidth falls within the S-band frequency (2-4 GHz).

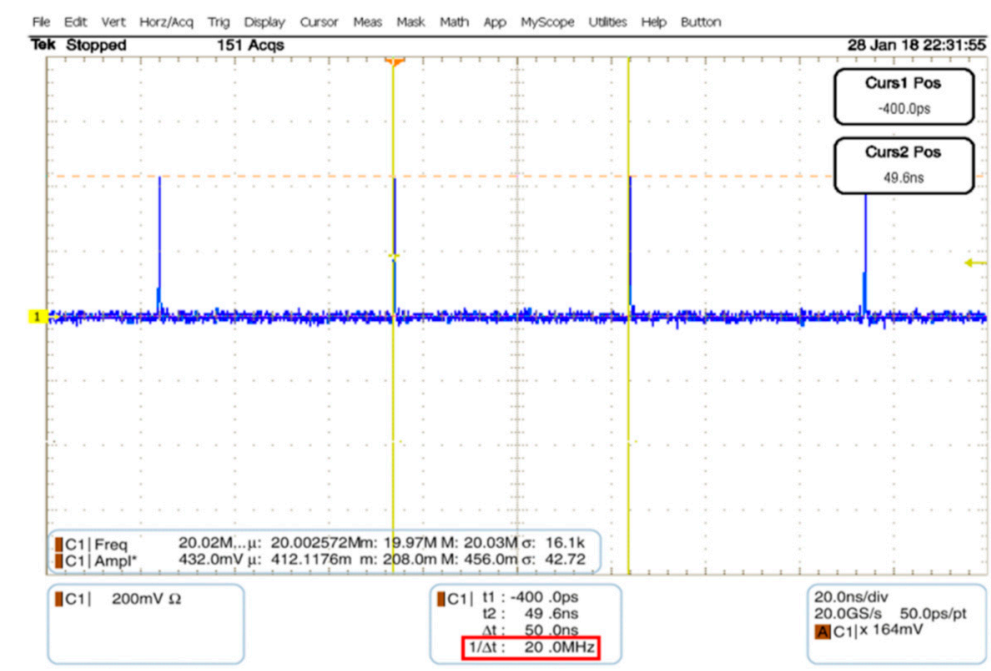

Figure 14. IR-UWB pulse generated by the FPGA scheme with pulse repetition frequency of $20 \mathrm{MHz}$ using digital oscilloscope. 

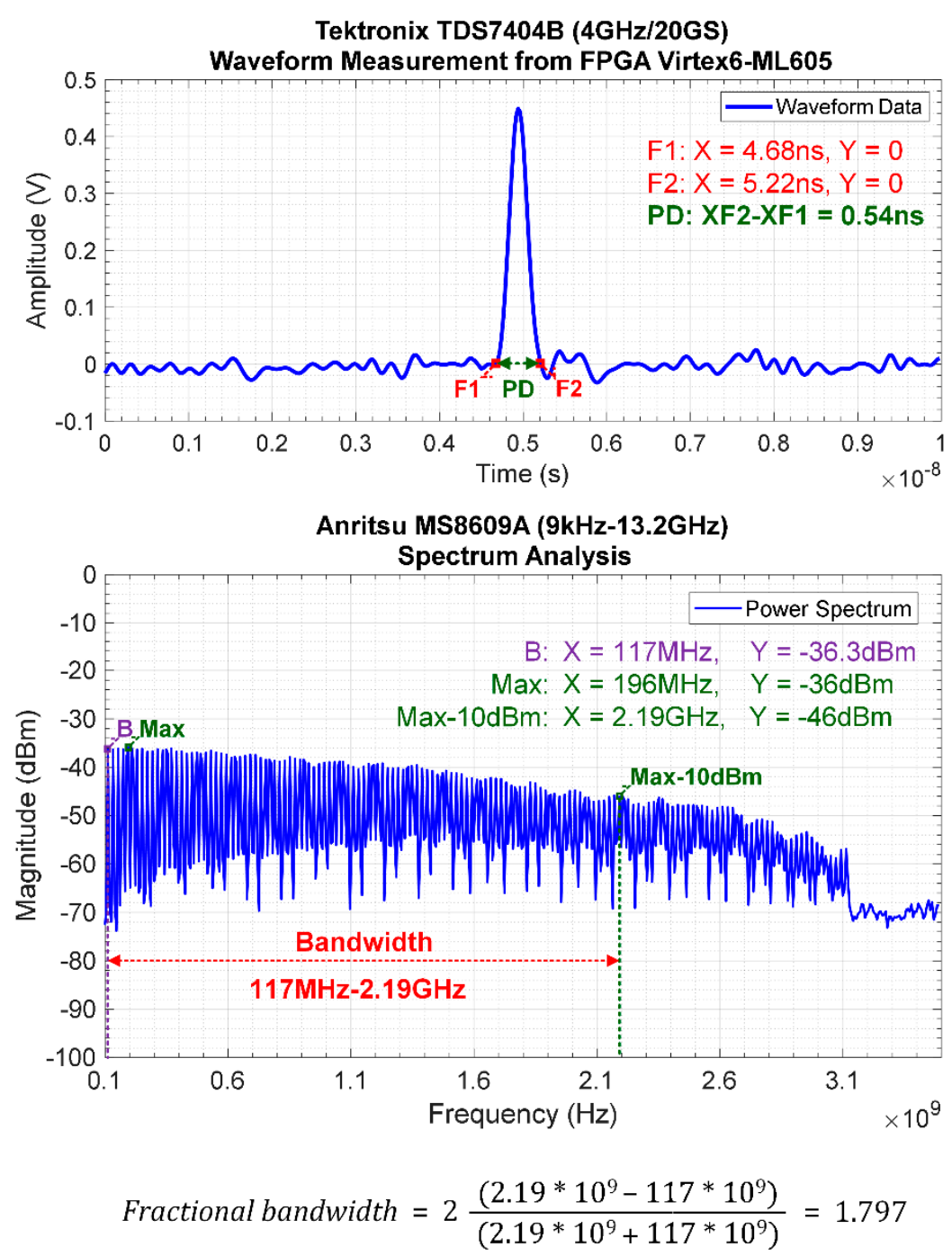

Figure 15. Pulse duration and bandwidth of IR-UWB generated by the FPGA scheme.

\subsection{Human Detection Performance of IR-UWB Radar System}

This sub-section discusses the performance of the proposed IR-UWB radar system to detect human respiration and locate the human subjects underneath the rubble (range estimation). As previously stated, this research used layers of stacked clay bricks to simulate detection of human subjects buried underneath the rubble. Since the detection results of the six participating human subjects are insignificantly different, this part thus presents the findings of one single participant.

\subsubsection{Respiratory Rate Estimation}

Figure 16a-c respectively illustrates the respiratory frequency of a human subject in supine position under layers of stacked clay bricks: $3(9 \mathrm{~cm}), 6(18 \mathrm{~cm})$, and 9 layers $(27 \mathrm{~cm})$, using the IR-UWB radar system and respiration sensor. The experimental respiratory frequency, as indicated by the maximum frequency peak, are $0.3842 \mathrm{~Hz}$ ( 23 breaths/min), $0.2938 \mathrm{~Hz}$ (17.6 breaths/min), and $0.3111 \mathrm{~Hz}$ (18.7 breaths/min) for 3, 6, and 9 layers of stacked bricks. The corresponding benchmark respiratory frequency, as measured by the respiration sensor, are $0.3878 \mathrm{~Hz}(23.3$ breaths $/ \mathrm{min}), 0.2888 \mathrm{~Hz}$ (17.3 breaths/min), and $0.3017 \mathrm{~Hz}$ (18.1 breaths/min). The experimental and benchmark respiratory rates are in good agreement, suggesting that the proposed IR-UWB radar system is applicable to localization of human buried underneath the rubble. 


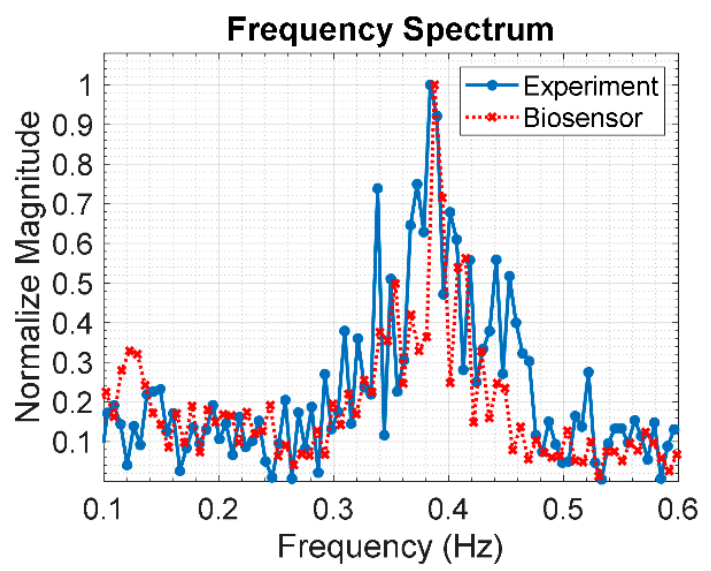

(a)

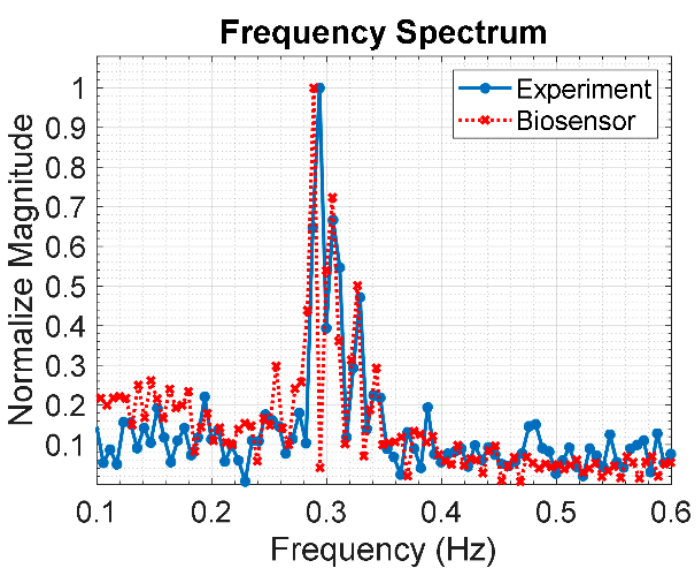

(b)

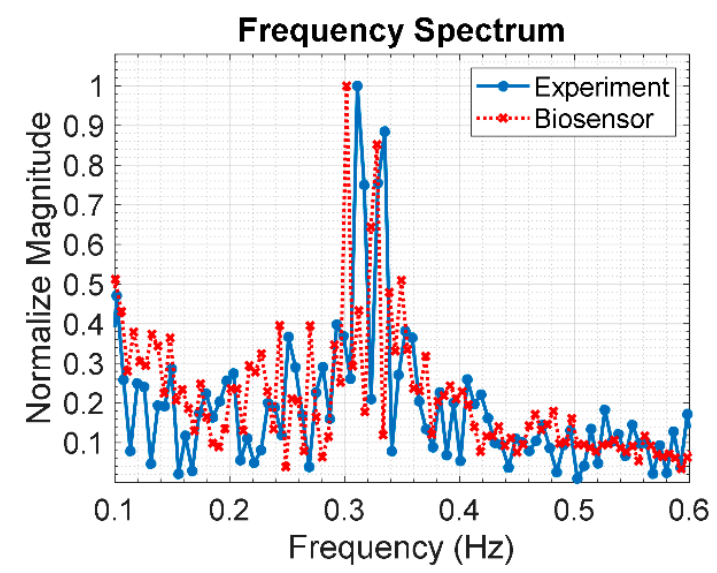

(c)

Figure 16. Respiratory frequency of a human subject in supine position under layers of stacked clay bricks, using IR-UWB radar system and respiration sensor: (a) 3 layers $(9 \mathrm{~cm})$; (b) 6 layers $(18 \mathrm{~cm})$; (c) 9 layers $(27 \mathrm{~cm})$.

Figure 17a-c respectively depicts the respiratory frequency of the human subject in the prone position under different thicknesses of clay bricks: 9 (3 layers), 18 (6 layers), and $27 \mathrm{~cm}$ (9 layers), using the IR-UWB radar system and respiration sensor. The experimental respiratory frequencies are $0.2890 \mathrm{~Hz}$ (17.3 breaths/min), $0.2694 \mathrm{~Hz}$ (16.2 breaths/min), and $0.3621 \mathrm{~Hz}$ (21.7 breaths/min) for 3, 6, and 9 layers of stacked bricks. The corresponding benchmark respiratory frequency, as measured by the respiration sensor, are $0.2781 \mathrm{~Hz}(16.7$ breaths/min), $0.2738 \mathrm{~Hz}(16.4$ breaths/min), and $0.3531 \mathrm{~Hz}$ (21.2 breaths/min). The experimental and benchmark respiratory rates are in good agreement, indicating that the IR-UWB radar system is applicable to human localization underneath the rubble.

\subsubsection{Range Estimation Based on Doppler Frequency}

Figure 18a-c respectively shows the estimated range of the human subject in supine position under different thicknesses of stacked clay bricks: 9 (3 layers), 18 (6 layers), and 27 cm (9 layers). In range estimation, the statistical 7 th moment is used to locate human subjects underneath the rubble. The estimated distances (range) between the radar antennas and the human subject are 22.33, 35.08 , and $46.32 \mathrm{~cm}$ for 3, 6, and 9 layers of stacked bricks. Meanwhile, the corresponding distances, as measured by laser measuring device, are $24.5,33.5$, and $42.5 \mathrm{~cm}$. The experimental and measured 
results are in good agreement, indicating the applicability of the IR-UWB radar system for human localization underneath the rubble.

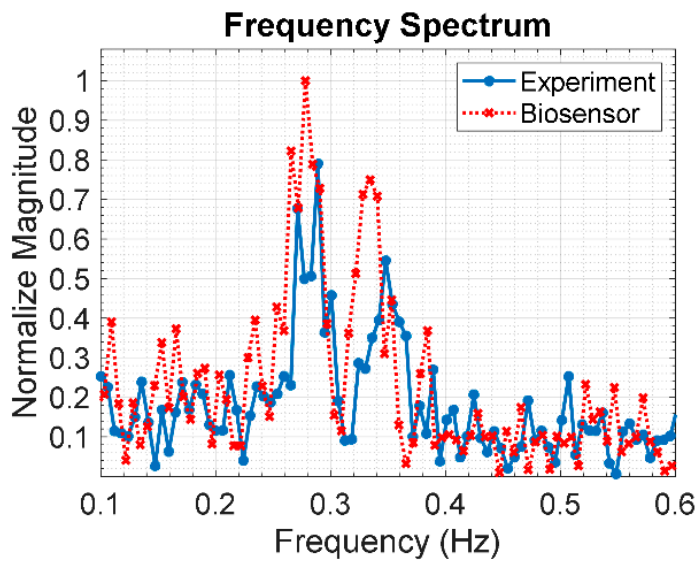

(a)

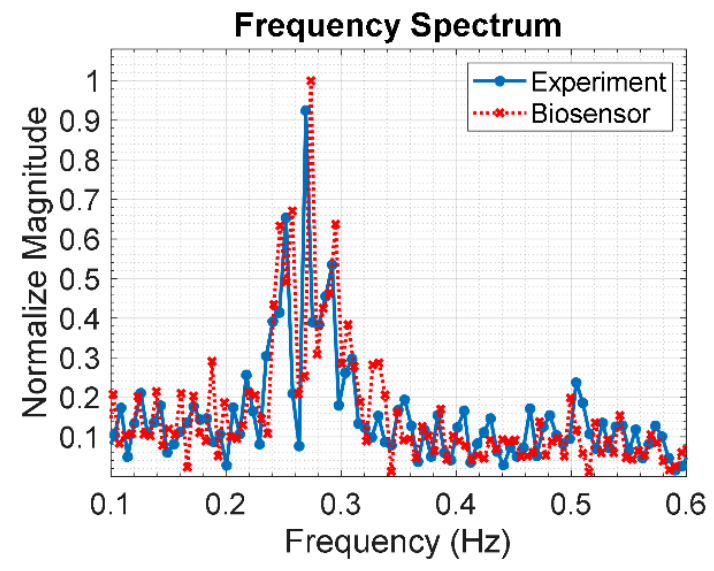

(b)

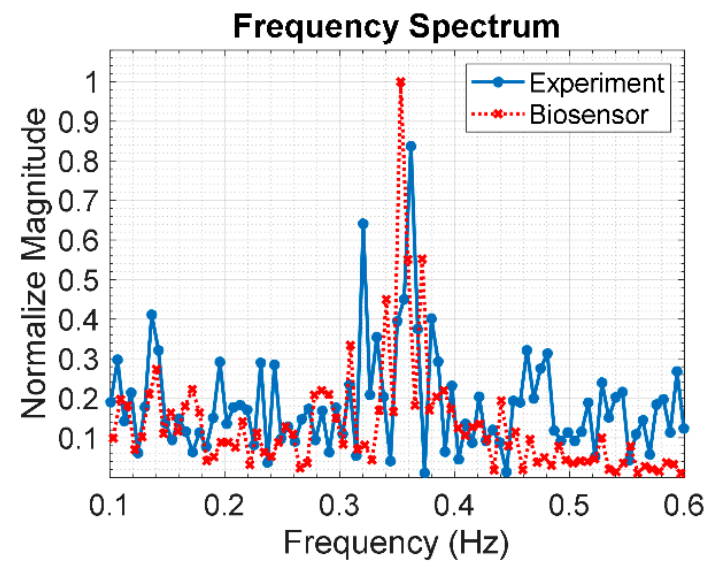

(c)

Figure 17. Respiratory frequency of a human subject in prone position under layers of stacked clay bricks, using IR-UWB radar system and respiration sensor: (a) 3 layers $(9 \mathrm{~cm})$; $(\mathbf{b}) 6$ layers $(18 \mathrm{~cm})$; (c) 9 layers $(27 \mathrm{~cm})$.

Figure $19 a-c$ respectively illustrate the estimated range of the human subject in prone position under different thicknesses of clay bricks: 9 (3 layers), 18 (6 layers), and $27 \mathrm{~cm}$ (9 layers). The estimated distances between the antennas and human subject are 25.18, 37.32, and $48.72 \mathrm{~cm}$ for 3, 6, and 9 layers of stacked bricks. The corresponding distances, as measured by laser measuring device, are 25.5, 34.5 , and $43.5 \mathrm{~cm}$. The experimental and measured results are in good agreement. As illustrated in Figures 18 and 19, statistical 7th moment improves the range estimation performance of the IR-UWB radar system, vis-à-vis DFT. 

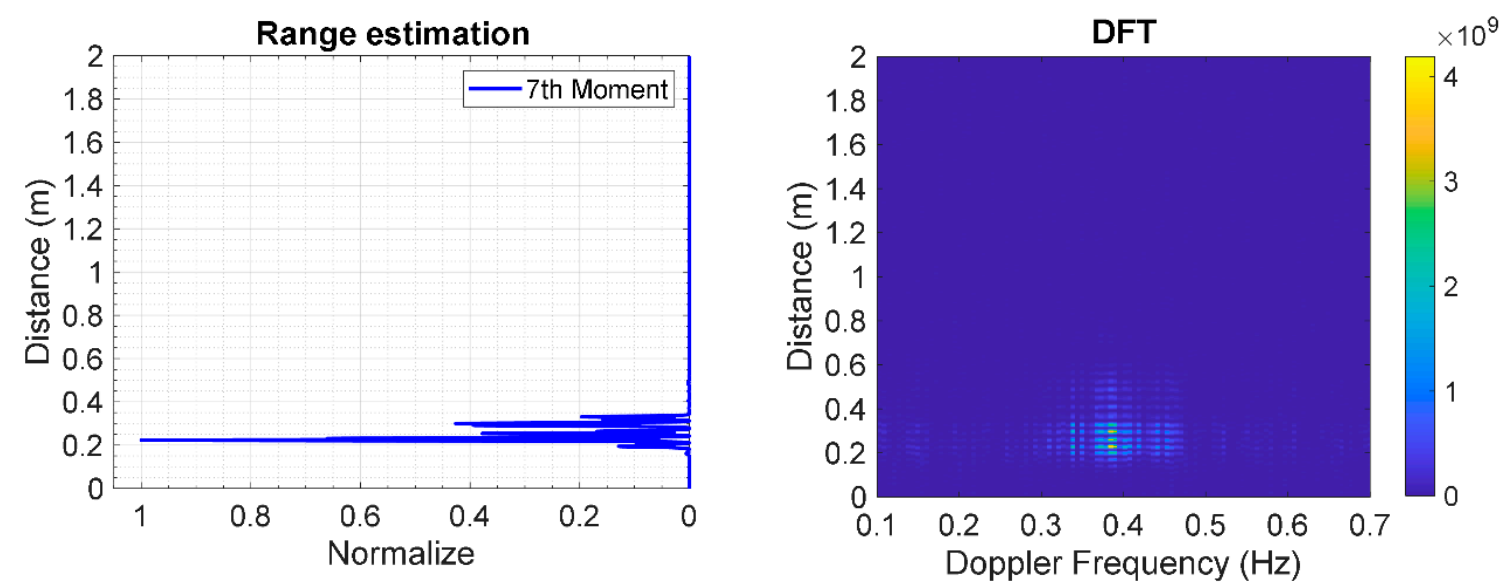

(a)
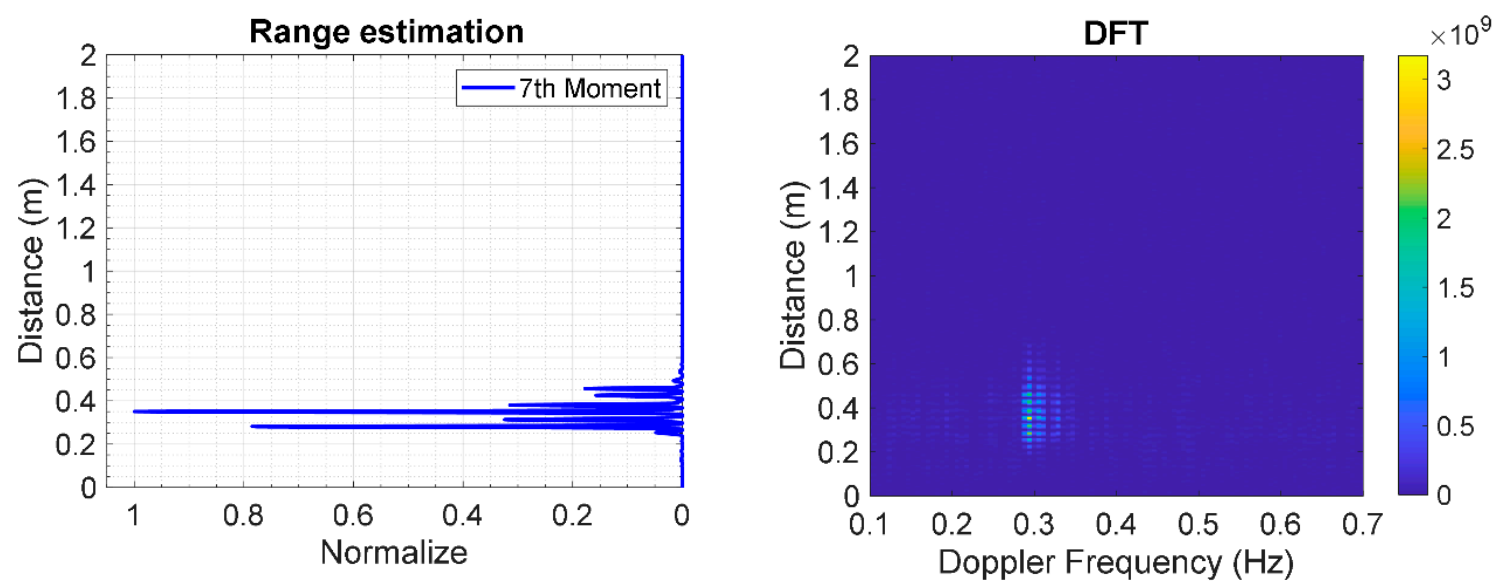

(b)
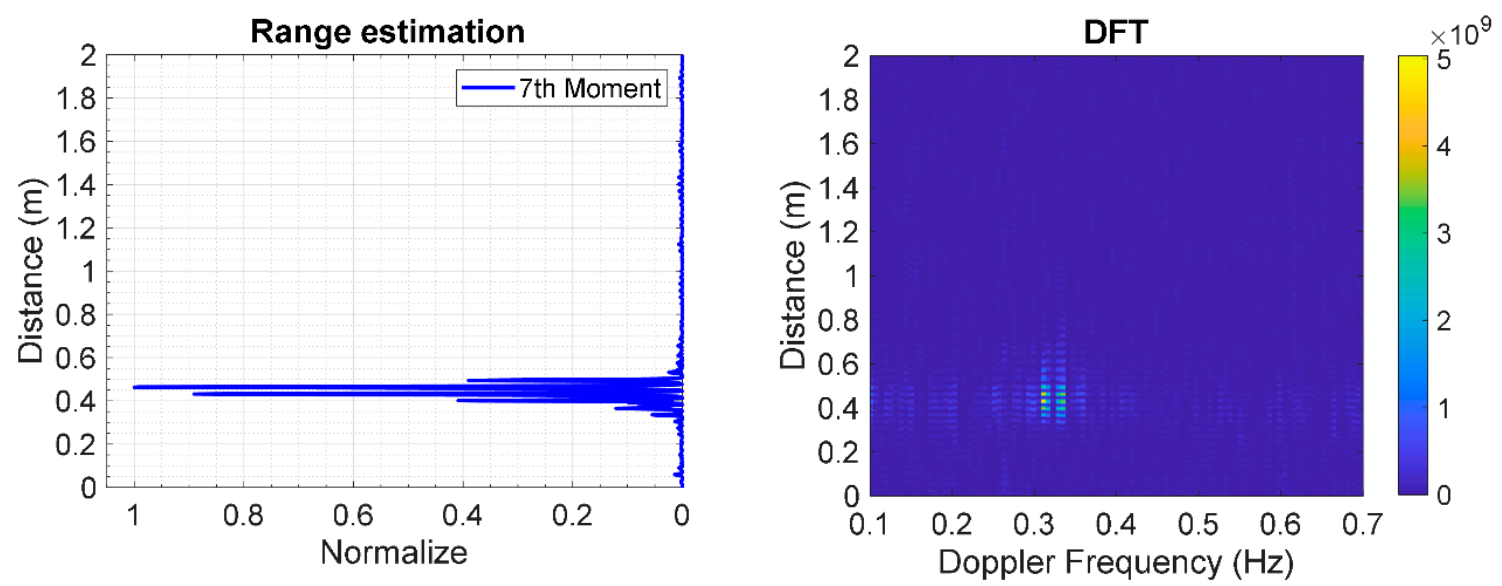

(c)

Figure 18. Statistical 7th-moment range estimation of a human subject in supine position under layers of stacked clay bricks using IR-UWB radar system: (a) 3 layers $(9 \mathrm{~cm})$; (b) 6 layers $(18 \mathrm{~cm})$; (c) 9 layers $(27 \mathrm{~cm})$. 

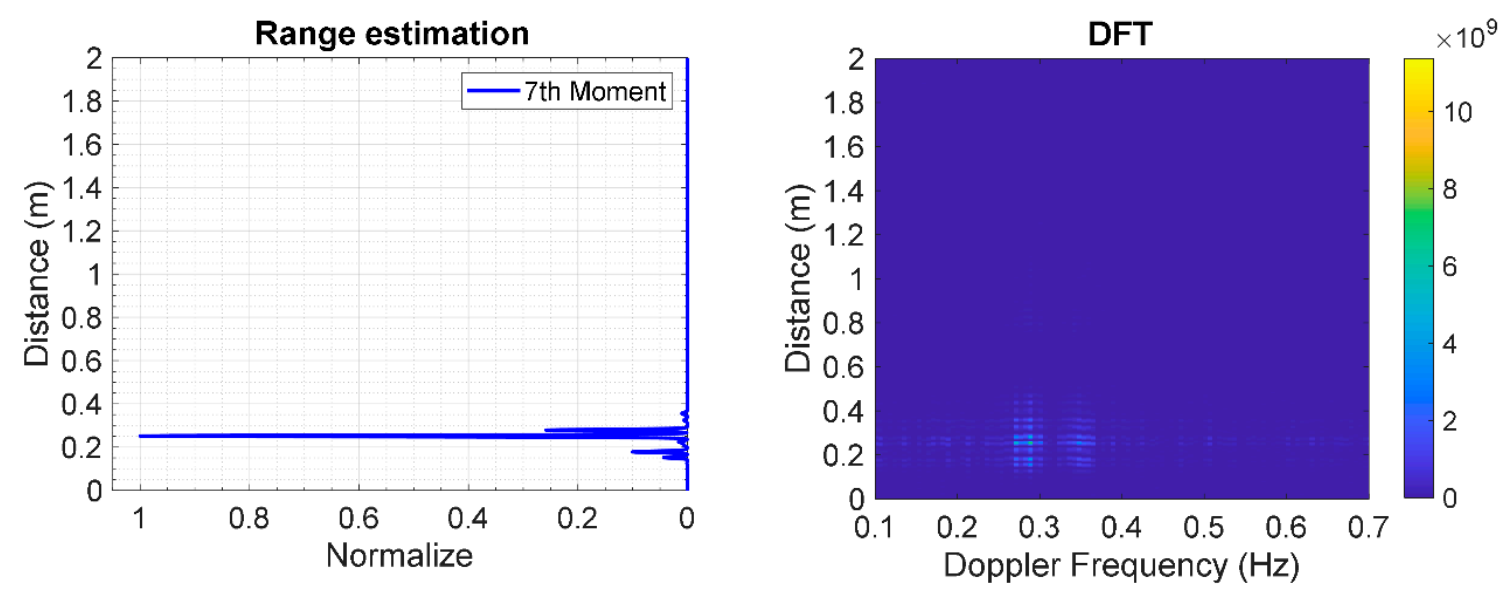

(a)
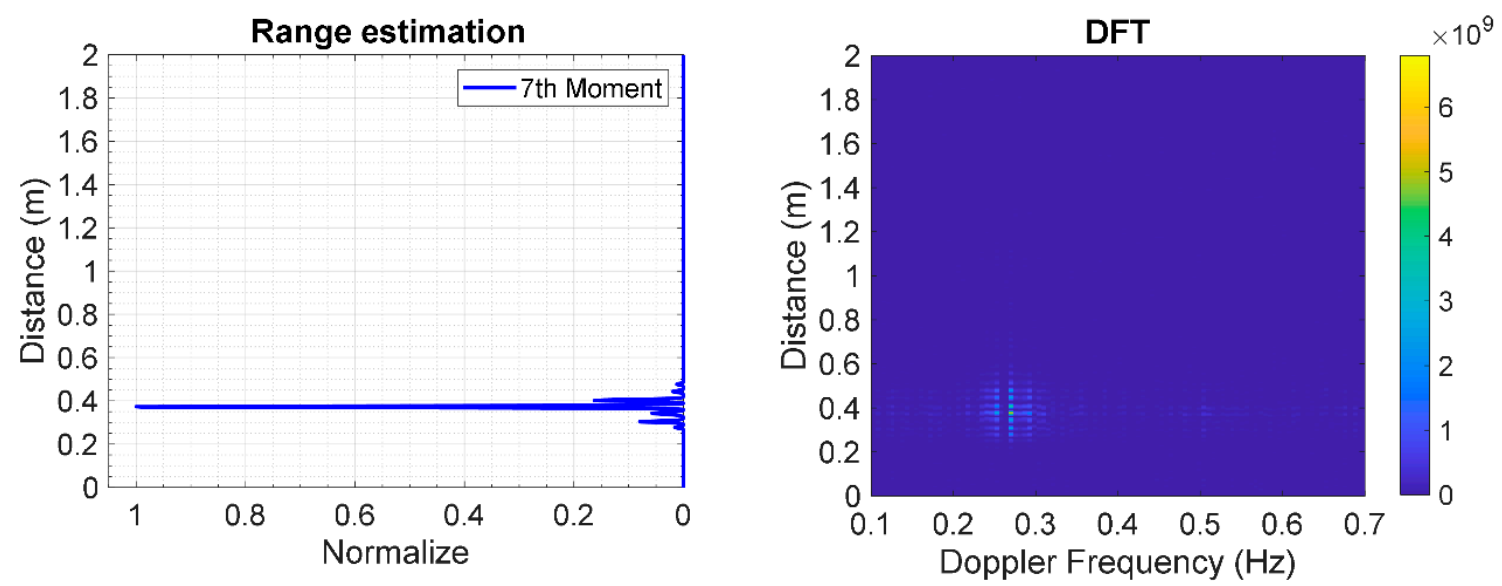

(b)
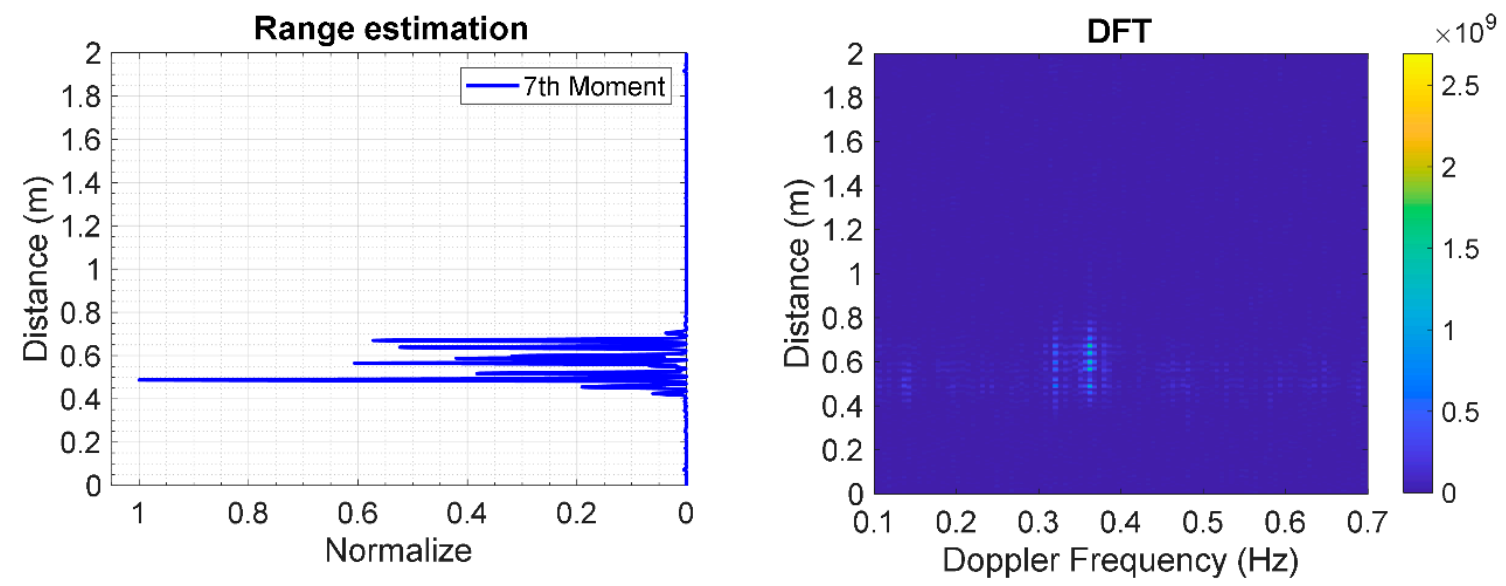

(c)

Figure 19. Statistical 7th-moment range estimation of a human subject in prone position under layers of stacked clay bricks using IR-UWB radar system: (a) 3 layers $(9 \mathrm{~cm})$; (b) 6 layers $(18 \mathrm{~cm})$; (c) 9 layers $(27 \mathrm{~cm})$.

\section{Conclusions}

This research proposes an FPGA scheme to generate an IR-UWB pulse based on four time-delay paths using LUT four-input XOR gate. The FPGA scheme consists of three parts: digital clock manager, 
delay path stratagem, and edge combiner. The IR-UWB radar system is designed to detect from respiration live humans buried underneath the rubble in the wake of an earthquake. The IR-UWB radar system is also capable of estimating the range to locate human subjects buried underneath. Discrete fast Fourier transform is utilized to detect the respiration in terms of Doppler frequency, and the statistical 7 th moment is used to locate human subjects underneath the rubble. Experiments were carried out with human subjects lying underneath different layers of stacked clay bricks in supine and prone position. The results show that the IR-UWB radar system achieves a pulse duration of $540 \mathrm{ps}$ and a bandwidth of $2.073 \mathrm{GHz}(117 \mathrm{MHz}-2.19 \mathrm{GHz}$, fractional bandwidth of 1.797). In respiration detection, the experimental results are in good agreement with the respiration sensor readings, indicating that the IR-UWB radar system is capable of human detection underneath the rubble. In addition, the estimated ranges of the human location buried underneath using the IR-UWB radar system are agreeable with those measured by a laser measuring device. In essence, the proposed technology could be further improved for rescue operation in the aftermath of an earthquake.

Author Contributions: Conceptualization, L.T.; methodology, L.T. and P.P.; validation, L.T. and P.P.; formal analysis, L.T. and P.P.; investigation, L.T. and P.P.; writing-original draft preparation, L.T.; writing-review and editing, L.T. and P.P.; funding acquisition, P.P. All authors have read and agreed to the published version of the manuscript.

Funding: This research was funded by Faculty of Engineering, King Mongkut's Institute of Technology Ladkrabang, Bangkok, 10520, Thailand.

Acknowledgments: This research could not be success without technical supporting from BURN laboratory staff of KMITL. The most important is encouragement and other supporting from our parents and family.

Conflicts of Interest: The authors declare no conflict of interest.

\section{References}

1. Guarnieri, M. The Early History of Radar [Historical]. IEEE Ind. Electron. Mag. 2010, 4, 36-42. [CrossRef]

2. Miguelez, C.G.; Huyart, B.; Bergeault, E.; Jallet, L.P. New Automobile Radar Based on the Six-Port Phase/Frequency Discriminator. IEEE Trans. Veh. Technol. 2000, 49, 1416-1423. [CrossRef]

3. Xu, S.; Baker, C.J.; Pooni, S. Range and Doppler Cell Migration in Wideband Automotive Radar. IEEE Trans. Veh. Technol. 2019, 68, 5527-5536. [CrossRef]

4. Feng, Z.; Li, M.; Stolz, M.; Kunert, M.; Wiesbeck, W. Lane Detection with a High-Resolution Automotive Radar by Introducing a New Type of Road Marking. IEEE Trans. Intell. Transp. Syst. 2019, 20, 2430-2447. [CrossRef]

5. Sim, H.; Lee, S.; Lee, B.; Kim, S. Road structure classification through artificial neural network for automotive radar systems. IET RadarSonar Navig. 2019, 13, 1010-1017. [CrossRef]

6. Fernandez, M.G.; Lopez, Y.A.; Valdes, B.G.; Vaqueiro, Y.R.; Andres, F.L.; Garcia, A.P. Synthetic Aperture Radar Imaging System for Landmine Detection Using a Ground Penetrating Radar on Board a Unmanned Aerial Vehicle. IEEE Access 2018, 6, 45100-45112. [CrossRef]

7. Sipos, D.; Gleich, D. A Lightweight and Low-Power UAV-Borne Ground Penetrating Radar Design for Landmine Detection. Sensors 2020, 20, 2234. [CrossRef]

8. Gonzalez-Huici, M.A.; Catapano, I.; Soldovieri, F. A Comparative Study of GPR Reconstruction Approaches for Landmine Detection. IEEE J. Sel. Top. Appl. Earth Obs. Remote Sens. 2014, 7, 4869-4878. [CrossRef]

9. Migliaccio, M.; Nunziata, F.; Montuori, A.; Li, X.; Pichel, W.G. A Multifrequency Polarimetric SAR Processing Chain to Observe Oil Fields in the Gulf of Mexico. IEEE Trans. Geosci. Remote Sens. 2011, 49, 4729-4737. [CrossRef]

10. Buhari, M.D.; Tian, G.; Tiwari, R. Microwave-Based SAR Technique for Pipeline Inspection Using Autofocus Range-Doppler Algorithm. IEEE Sens. J. 2019, 19, 1777-1787. [CrossRef]

11. Damini, A.; McDonald, M.; Haslam, G.E. X-band wideband experimental airborne radar for SAR, GMTI and maritime surveillance. IEE Proc. Radar Sonar Navig. 2003, 150, 305. [CrossRef]

12. Reigber, A.; Scheiber, R.; Jager, M.; Prats-Iraola, P.; Hajnsek, I.; Jagdhuber, T.; Papathanassiou, K.P.; Nannini, M.; Aguilera, E.; Baumgartner, S.; et al. Very-High-Resolution Airborne Synthetic Aperture Radar Imaging: Signal Processing and Applications. Proc. IEEE 2013, 101, 759-783. [CrossRef] 
13. Gallego, A.-J.; Gil, P.; Pertusa, A.; Fisher, R.B. Segmentation of Oil Spills on Side-Looking Airborne Radar Imagery with Autoencoders. Sensors 2018, 18, 797. [CrossRef] [PubMed]

14. Liu, L.; Liu, Z.; Barrowes, B.E. Through-Wall Bio-Radiolocation with UWB Impulse Radar: Observation, Simulation and Signal Extraction. IEEE J. Sel. Top. Appl. Earth Obs. Remote Sens. 2011, 4, 791-798. [CrossRef]

15. Li, C.; Lubecke, V.M.; Boric-Lubecke, O.; Lin, J. A Review on Recent Advances in Doppler Radar Sensors for Noncontact Healthcare Monitoring. IEEE Trans. Microw. Theory Tech. 2013, 61, 2046-2060. [CrossRef]

16. Droitcour, A.D.; Boric-Lubecke, O.V.; Lubecke, M.; Lin, J.; Kovacs, G.T.A. Range correlation and I/Q performance benefits in single-chip silicon Doppler radars for noncontact cardiopulmonary monitoring. IEEE Trans. Microw. Theory Tech. 2004, 52, 838-848. [CrossRef]

17. Li, C.; Lin, J.; Xiao, Y. Robust Overnight Monitoring of Human Vital Signs by a Non-contact Respiration and Heartbeat Detector. In Proceedings of the 2006 International Conference of the IEEE Engineering in Medicine and Biology Society, New York, NY, USA, 30 August-3 September 2006.

18. Li, C.; Ling, J.; Li, J.; Lin, J. Accurate Doppler Radar Noncontact Vital Sign Detection Using the RELAX Algorithm. IEEE Trans. Instrum. Meas. 2010, 59, 687-695.

19. Lin, F.; Zhuang, Y.; Song, C.; Wang, A.; Li, Y.; Gu, C.; Li, C.; Xu, W. SleepSense: A Noncontact and Cost-Effective Sleep Monitoring System. IEEE Trans. Biomed. Circuits Syst. 2017, 11, 189-202. [CrossRef]

20. Hong, H.; Zhang, L.; Gu, C.; Li, Y.; Zhou, G.; Zhu, X. Noncontact Sleep Stage Estimation Using a CW Doppler Radar. IEEE J. Emerg. Sel. Top. Circuits Syst. 2018, 8, 260-270. [CrossRef]

21. Zhao, H.; Hong, H.; Miao, D.; Li, Y.; Zhang, H.; Zhang, Y.; Li, C.; Zhu, X. A Noncontact Breathing Disorder Recognition System Using 2.4-GHz Digital-IF Doppler Radar. IEEE J. Biomed. Health Inform. 2019, 23, $208-217$. [CrossRef]

22. Chuang, H.; Chen, Y.; Chen, K. Automatic clutter-canceler for microwave life-detection systems. IEEE Trans. Instrum. Meas. 1991, 40,747-750. [CrossRef]

23. Chen, K.; Huang, Y.; Zhang, J.; Norman, A. Microwave life-detection systems for searching human subjects under earthquake rubble or behind barrier. IEEE Trans. Biomed. Eng. 2000, 47, 105-114. [CrossRef] [PubMed]

24. Gennarelli, G.; Ludeno, G.; Soldovieri, F. Real-Time Through-Wall Situation Awareness Using a Microwave Doppler Radar Sensor. Remote Sens. 2016, 8, 621. [CrossRef]

25. Baker, C.J.; Piper, S.O. Continuous Wave Radar. In Principles of Modern Radar: Radar Applications, 1st ed.; Melvin, W.L., Scheer, J.A., Eds.; Institution of Engineering and Technology: Stevenage, UK, 2013; Volume 3 , pp. 17-85.

26. Wang, F.; Horng, T.; Peng, K.; Jau, J.; Li, J.; Chen, C. Detection of Concealed Individuals Based on Their Vital Signs by Using a See-Through-Wall Imaging System With a Self-Injection-Locked Radar. IEEE Trans. Microw. Theory Tech. 2013, 61, 696-704. [CrossRef]

27. Jia, Y.; Guo, Y.; Yan, C.; Sheng, H.; Cui, G.; Zhong, X. Detection and Localization for Multiple Stationary Human Targets Based on Cross-Correlation of Dual-Station SFCW Radars. Remote Sens. 2019, 11, 1428. [CrossRef]

28. Liu, L.; Liu, S. Remote Detection of Human Vital Sign with Stepped-Frequency Continuous Wave Radar. IEEE J. Sel. Top. Appl. Earth Obs. Remote Sens. 2014, 7, 775-782. [CrossRef]

29. Sisma, O.; Gaugue, A.; Liebe, C.; Ogier, J.M. UWB radar: Vision through a wall. Telecommun. Syst. 2008, 38, 53-59. [CrossRef]

30. Fontana, R.J. Recent system applications of short-pulse ultra-wideband (UWB) technology. IEEE Trans. Microw. Theory Tech. 2004, 52, 2087-2104. [CrossRef]

31. Li, J.; Zeng, Z.; Sun, J.; Liu, F. Through-Wall Detection of Human Being's Movement by UWB Radar. IEEE Geosci. Remote Sens. Lett. 2012, 9, 1079-1083. [CrossRef]

32. Immoreev, I.I.; Fedotov, D.V. Ultra wideband radar systems: Advantages and disadvantages. In Proceedings of the 2002 IEEE Conference on Ultra Wideband Systems and Technologies, Baltimore, MD, USA, 21-23 May 2002.

33. Liang, F.; Qi, F.; An, Q.; Lv, H.; Chen, F.; Li, Z.; Wang, J. Detection of Multiple Stationary Humans Using UWB MIMO Radar. Sensors 2016, 16, 1922. [CrossRef]

34. Dubey, R. Introduction to Embedded System Design Using Field Programmable Gate Arrays, 1st ed.; Springer Publishing Company: London, UK, 2009; pp. 10-12. 
35. Contreras-Medina, L.M.; Romero-Troncoso, R.J.; Millan-Almaraz, J.R.; Rodriguez-Donate, C. FPGA based multiple-channel vibration analyzer embedded system for industrial applications in automatic failure detection. In Proceedings of the 2008 International Symposium on Industrial Embedded Systems, Le Grande Motte, France, 25 July 2008.

36. Vyas, S.; Kumar, N.G.; Zambreno, J.; Gill, C.; Cytron, R.; Jones, P. An FPGA-Based Plant-on-Chip Platform for Cyber-Physical System Analysis. IEEE Embed. Syst. Lett. 2014, 6, 4-7. [CrossRef]

37. Cristo, A.; Fisher, K.; Gualtieri, J.; Pérez, R.M.; Martínez, P. Optimization of Processor-to-Hardware Module Communications on Spaceborne Hybrid FPGA-based Architectures. IEEE Embed. Syst. Lett. 2013, 5, 77-80. [CrossRef]

38. Yang, Y.; Fathy, A.E. Development and Implementation of a Real-Time See-Through-Wall Radar System Based on FPGA. IEEE Trans. Geosci. Remote Sens. 2009, 47, 1270-1280. [CrossRef]

39. Wang, Y.; Liu, Q.; Fathy, A.E. CW and Pulse-Doppler Radar Processing Based on FPGA for Human Sensing Applications. IEEE Trans. Geosci. Remote Sens. 2013, 51, 3097-3107. [CrossRef]

40. Liang, C.; Liu, S.; Liu, S. A Calibrated Pulse Generator for Impulse-Radio UWB Applications. IEEE J. Solid-State Circuits 2006, 41, 2401-2407. [CrossRef]

41. Wentzloff, D.D.; Chandrakasan, A.P. A 47pJ/pulse 3.1-to-5GHz All-Digital UWB Transmitter in 90nm CMOS. In Proceedings of the 2007 IEEE International Solid-State Circuits Conference. Digest of Technical Papers, San Francisco, CA, USA, 11-15 February 2007.

42. Ryckaert, J.; Desset, C.; Fort, A.; Badaroglu, M.; De Heyn, V.; Wambacq, P.; Van der Plas, G.; Donnay, S.; Van Poucke, B.; Gyselinckx, B. Ultra-wide-band transmitter for low-power wireless body area networks: Design and evaluation. IEEE Trans. Circuits Syst. I Regul. Pap. 2005, 52, 2515-2525. [CrossRef]

43. Park, Y.; Wentzloff, D.D. All-digital synthesizable UWB transmitter architectures. In Proceedings of the 2008 IEEE International Conference on Ultra-Wideband, Hannover, Germany, 10-12 September 2008.

44. Tantiparimongkol, L.; Phasukkit, P. Experiment of UWB Pulse Generator using FPGA based on Delay Line-Based Pulse Generation for Radar Application. In Proceedings of the 2018 International Symposium on Multimedia and Communication Technology (ISMAC), Tottori, Japan, 29-31 August 2018.

45. Tantiparimongkol, L.; Phasukkit, P. Designing of UWB Pulse Generation in FPGA Based on Delay Line Method for Human Range Through the Wall Detecting Application. In Proceedings of the 2019 16th International Conference on Electrical Engineering/Electronics, Computer, Telecommunications and Information Technology (ECTI-CON), Pattaya, Thailand, 10-13 July 2019.

46. Ghavami, M.; Michael, L.B.; Haruyama, S.; Kohno, R. A Novel UWB Pulse Shape Modulation System. Wirel. Pers. Commun. 2002, 23, 105-120. [CrossRef]

47. Ma, L.; Khorasani, K. Constructive feedforward neural networks using Hermite polynomial activation functions. IEEE Trans. Neural Netw. 2005, 16, 821-833. [CrossRef]

48. Chen, X.; Kiaei, S. Monocycle shapes for ultra wideband system. In Proceedings of the 2002 IEEE International Symposium on Circuits and Systems, Phoenix-Scottsdale, AZ, USA, 26-29 May 2002.

49. Virtex-6 Family Overview (DS150). Available online: https://www.xilinx.com/support/documentation/data_ sheets/ds150.pdf (accessed on 9 May 2020).

50. PlanAhead User Guide (UG632). Available online: https://www.xilinx.com/support/documentation/sw_ manuals/xilinx14_7/PlanAhead_UserGuide.pdf (accessed on 5 May 2020).

51. Venkatesh, S.; Anderson, C.R.; Rivera, N.V.; Buehrer, R.M. Implementation and analysis of respiration-rate estimation using impulse-based UWB. In Proceedings of the MILCOM 2005-2005 IEEE Military Communications Conference, Atlantic City, NJ, USA, 20 March 2006.

52. Xu, Y.; Chen, J.; Dai, S.; Fang, G. Experimental Study of UWB Pulse Radar for Life Detection. In Proceedings of the 2011 First International Conference on Instrumentation, Measurement, Computer, Communication and Control, Beijing, China, 21-23 October 2011.

53. Xu, Y.; Dai, S.; Wu, S.; Chen, J.; Fang, G. Vital Sign Detection Method Based on Multiple Higher Order Cumulant for Ultrawideband Radar. IEEE Trans. Geosci. Remote Sens. 2012, 50, 4. [CrossRef]

54. Liang, X.; Zhang, H.; Fang, G.; Ye, S.; Gulliver, T.A. An Improved Algorithm for Through-Wall Target Detection Using Ultra-Wideband Impulse Radar. IEEE Access 2017, 5, 22101-22118. [CrossRef]

55. Liang, X.; Lv, T.; Zhang, H.; Gao, Y.; Fang, G. Through-wall human being detection using UWB impulse radar. Eurasip J. Wirel. Commun. Netw. 2018, 2018, 46. [CrossRef] 
56. Rittiplang, A.; Phasukkit, P. UWB Radar for Multiple Human Detection through the Wall Based on Doppler Frequency and Variance Statistic. In Proceedings of the 2019 12th Biomedical Engineering International Conference (BMEiCON), Ubon Ratchathani, Thailand, 19-22 November 2019.

57. Xu, Y.; Wu, S.; Chen, C.; Chen, J.; Fang, G. A Novel Method for Automatic Detection of Trapped Victims by Ultrawideband Radar. IEEE Trans. Geosci. Remote Sens. 2012, 50, 3132-3142. [CrossRef]

(C) 2020 by the authors. Licensee MDPI, Basel, Switzerland. This article is an open access article distributed under the terms and conditions of the Creative Commons Attribution (CC BY) license (http://creativecommons.org/licenses/by/4.0/). 